\title{
WestVirginiaUniversity
}

THE RESEARCH REPOSITORY @ WVU

Graduate Theses, Dissertations, and Problem Reports

1998

\section{Fluency and controlled-operant training methods}

\author{
Finnur Oddsson \\ West Virginia University
}

Follow this and additional works at: https://researchrepository.wvu.edu/etd

\author{
Recommended Citation \\ Oddsson, Finnur, "Fluency and controlled-operant training methods" (1998). Graduate Theses, \\ Dissertations, and Problem Reports. 691. \\ https://researchrepository.wvu.edu/etd/691
}

This Thesis is protected by copyright and/or related rights. It has been brought to you by the The Research Repository @ WVU with permission from the rights-holder(s). You are free to use this Thesis in any way that is permitted by the copyright and related rights legislation that applies to your use. For other uses you must obtain permission from the rights-holder(s) directly, unless additional rights are indicated by a Creative Commons license in the record and/ or on the work itself. This Thesis has been accepted for inclusion in WVU Graduate Theses, Dissertations, and Problem Reports collection by an authorized administrator of The Research Repository @ WVU. For more information, please contact researchrepository@mail.wvu.edu. 
Fluency and Controlled-Operant Training Methods

\section{THESIS}

Submitted to the Eberly College of Arts and Sciences

of

West Virginia University

In Partial Fulfillment of the Requirements for

The Degree of Master of Arts

in

Psychology

by

Finnur Oddsson, B. A.

Morgantown, West Virginia

1998 


\section{Acknowledgements}

I would like to thank my committee, Phil Chase, Andy Lattal, and Anne Watson for their suggestions and helpful comments on the study. Special thanks go to Phil Chase who played a major role in the development of the study and was very helpful and patient in shaping my writing skills. I'm also especially indebted to Kevin J. Munson for invaluable help with the programming of the experiment. Finally, I'd like to thank my wife, Sigga, for moving with me to Morgantown from another continent, and for her understanding and support.

The study was funded in part by the Alumni Fund. 
Table of Contents

Acknowledgements................................................... ii

Table of Contents......................................................... iii

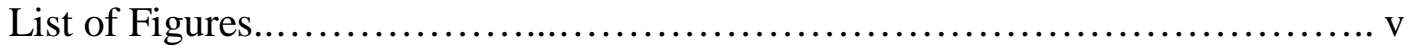

List of Tables....................................................... vii

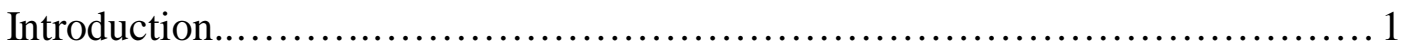

Fluency procedures................................................ 3

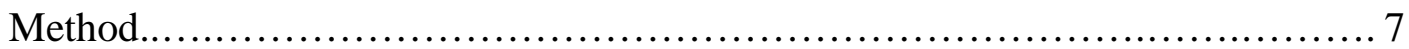

Subjects..................................................... 7

Settings and apparatus......................................... 8

General outline of experiment................................... 10

Procedures..................................................... 10

Results................................................................ 21

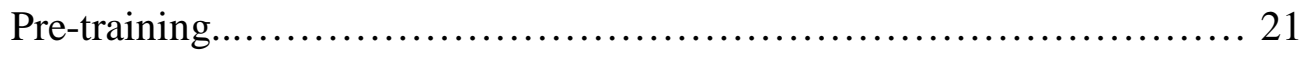

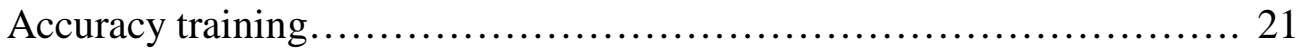

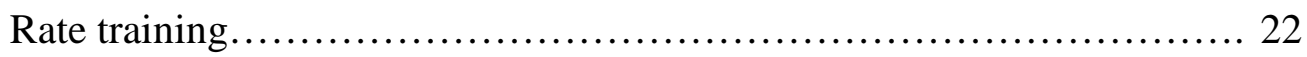

Test performance............................................. 25

Discussion....................................................... 50

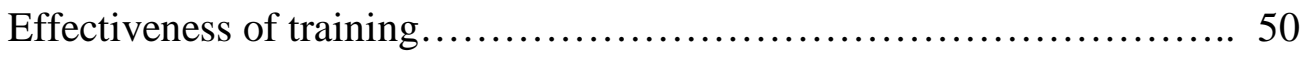

Efficiency of training........................................ 51

Important differences in test performance........................ 53 


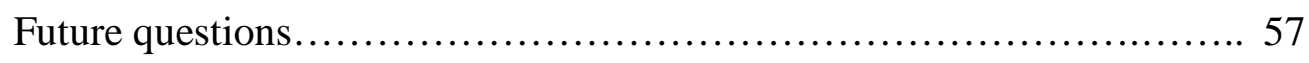

Conclusions............................................... 64

References...................................................... 65

Appendices

Appendix A: Subject Recruitment Form.......................... 68

Appendix B: Subject Selection Test.............................. 69

Appendix C: Informed Consent Form for 0s and 1.5s ITIs............. 70

Appendix D: Informed Consent Form for No ITIs.................. 72

Appendix E: Pre-training...................................... 74

Abstract......................................................... 77

Signature Page................................................... 78 


\section{List of Figures}

Figure 1. Correct and incorrect rate of responding per 1-minute timings as a function of training (1-minute timings) for representative subjects, $\mathrm{H} 07, \mathrm{H} 12$, and $\mathrm{H} 30$, from each training condition, $0 \mathrm{~s}, 1.5 \mathrm{~s}$, and No ITIs. $\mathrm{H} 12$ was yoked to $\mathrm{H} 07$ for practice. The circles represent correct responding and the triangles incorrect responding per 1-minute timings................. 26

Figure 2. Average accuracy of responding on all tasks across training conditions on Pretests, Post Accuracy, Post Rate, and Retention tests. Circles represent Trials and triangles represent Multi-trial presentation modes. The top panel shows trained binary numbers, the middle panel shows untrained binary numbers, and the bottom shows math problems

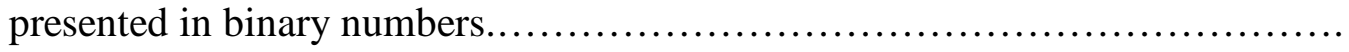

Figure 3. Average number of correct responses (trials) per minute to trained binary numbers on Pretests, Post Accuracy, Post Rate, and Retention tests for the three training methods. Black bars represent 0s ITIs training, gray bars represent 1.5s ITIs training and white bars represent No ITIs training. The upper panel shows test results when Trial presentations were used and the lower shows results for Multi-trial presentations. The error bars represent standard deviation. 
Figure 4. Average number of correct responses (trials) per minute to untrained binary numbers on Pretests, Post Accuracy, Post Rate, and Retention tests for the three training methods. Black bars represent 0s ITIs training, gray bars represent $1.5 \mathrm{~s}$ ITIs training, and white bars represent No ITIs training. The upper panel shows testing using Trial presentations and the lower shows Multi-trial presentations. The error bars represent standard deviation....................................... 39

Figure 5. Average number of correct responses (trials) per minute to math problems in presented in binary numbers on Pretests, Post Accuracy, Post Rate, and Retention tests for the three training methods. Black bars represent 0s ITIs training, gray bars represent 1.5s ITIs training, and white bars represent No ITIs training. The upper panel shows testing using Trial presentations and the lower shows Multi-trial presentations. The error bars represent standard deviation......................................... 43 
List of Tables

Table 1. Experimental Phases for All Training Conditions and All Subjects

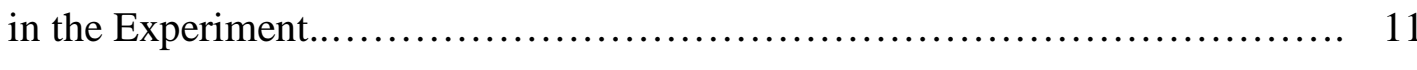

Table 2. Mean Performance Scores of Subjects in All Training Conditions During Rate Training. Standard deviations are presented within parenthesis.....

Table 3. The Mean Accuracy (\%) of Responding for All Subjects to Trained and Untrained Binary Numbers, and Math Problems in Binary on All Tests for Trial Presentations, Including Degrees of Freedom (Df) and F values for a Repeated Measures Analysis of Variance of the Three Tasks. The Lower Panel Shows Simple Comparisons Between Tasks at All Tests where $\mathrm{T}=$ Trained Trials, $\mathrm{U}=$ Untrained Trials, and $\mathrm{M}=$ Math Trials. 32

Table 4. The Mean Accuracy (\%) of Responding for All Subjects to Trained and Untrained Binary Numbers, and Math Problems in Binary on All Tests for Multi-trial Presentations, Including Degrees of Freedom (Df) and F values for a Repeated Measures Analysis of Variance of the Three Tasks. The Lower Panel Shows Simple Comparisons Between Tasks at All Tests where $\mathrm{T}=$ Trained Trials, $\mathrm{U}=$ Untrained Trials, and $\mathrm{M}=$ Math Trials

Table 5. Mean Number of Correct Responses to Trained Binary Numbers for Trials and Multi-trial Presentation Modes on All Tests, Collapsed Across Conditions 
Table 6. Mean Number of Correct Responses to Untrained Binary Numbers for Trials and Multi-trial Presentation Modes on All Tests, Collapsed Across Conditions............................................ 42

Table 7. Mean Number of Correct Response to Math Problems Presented in Binary Numbers for Trials and Multi-trial Presentation Modes on All Tests, Collapsed Across Conditions............................... 46

Table 8. The Mean Rate of Correct Responding for All Subjects to Trained and Untrained Binary Numbers, and Math Problems Presented in Binary on All Tests for Trial Presentations, Including Degrees of Freedom (Df) and F values for a Repeated Measures Analysis of Variance of the Three Tasks. The Lower Panel Shows Simple Comparisons Between Tasks at All Tests where $\mathrm{T}=$ Trained Trials, $\mathrm{U}=$ Untrained Trials, and $\mathrm{M}=$ Math Trials.......................... 48

Table 9. The Mean Rate of Correct Responding for All Subjects to Trained and Untrained Binary Numbers, and Math Problems Presented in Binary on All Tests for Multi-trial Presentations, Including Degrees of Freedom (Df) and F values for a Repeated Measures Analysis of Variance of the Three Tasks. The Lower Panel Shows Simple Comparisons Between Tasks at All Tests where $\mathrm{T}=$ Trained Trials, $\mathrm{U}=$ Untrained Trials, and $\mathrm{M}=$ Math Trials 
Fluency and Controlled-Operant Training Methods

Numerous criticisms of the US educational system cite evidence of poor basic skills and blame the lack of practice by students for these educational problems (Binder, 1993; Johnson \& Layng, 1992; Miller \& Heward, 1992; Wingert, 1996). Some of these same authors have identified a solution to these problems: the use of behavioral instructional and training techniques (Binder, 1993; Johnson \& Layng, 1992; Beck \& Clement, 1991). These techniques, which can be traced back to the applications of early behaviorists, such as Skinner's (1968) Programmed Instruction (PI) and Keller's (1968) Personalized System of Instruction (PSI), evolved from basic behavioral research on learning. Thus, they share many of the same features, such as breaking training material into small units, requiring mastery before students can move on to the next unit, allowing students to work at their own pace, and providing immediate feedback on test performance.

Most applications of behavioral principles have used accuracy, i.e., percentage correct scores, as a measure of performance or learning. This surprises some educators, because they claim that most of the major discoveries made by Skinner and his behavioral colleagues involved response rates as a standard measure of behavior (Binder, 1993). One behavioral training technique, Precision Teaching (PT), therefore, reintroduced the use of rate or frequency as a measure of performance (Lindsley, 1990). Lindsley argued that the addition of frequency measures provides a more sensitive method for assessing behavior. Accuracy measures impose a ceiling upon students' 
performance where all students who complete a task with $100 \%$ accuracy are classified as being equally skilled. Rate measures, however, enable educators to distinguish between performances on the basis of how many tasks can be completed in a set amount of time. Students who complete a different number of tasks per unit of time are considered to have different levels of skills.

This stress on rate allowed Lindsley to emphasize training not only to accurate mastery levels, but also to fluency levels. In general terms, fluency has been defined as “...the fluid combination of accuracy plus speed that characterizes competent performance" (Binder, 1988, 1993, 1996). This emphasis on speed, which is also found in the overlearning and automaticity literature (Dougherty \& Johnston, 1996), has been shown to produce various behavioral outcomes, such as improved retention, endurance, and the ability to apply the learned skills to more complex tasks (Binder, 1996; Johnson and Layng, 1994, 1996). Another important implication of fluency was suggested by Haughton (1972, as cited in Binder, 1996), who states that fluency on elementary or component skills was a prerequisite for fluency on advanced or composite skills. Haughton found that traditional reinforcement techniques failed to increase the frequency of composite behaviors when students were not fluent on component behaviors. Therefore, fluency on elementary skills served as a prerequisite for learning more complex skills (Binder, 1996).

Definitions of fluency have evolved to incorporate these behavioral outcomes. Johnson and Layng (1996), for instance, elaborated on Haughton's work to describe the 
RESAA standard, which specifies the functional criteria used to determine if certain skills or behaviors are fluent. The acronym stands for Retention, Endurance, Stability, Application and Adduction. Retention refers to a student's ability to maintain accuracy and rate of responding over an extended period of no practice. Endurance requires that a student be able to perform a skill at a rate criterion for time periods that are longer than the normal timings used in practice. Stability refers to a student's ability to engage in trained behavior in the face of distraction. Student should be able to apply (application) the learned skills to more complex tasks, and finally, they should show increasing capacity to learn new untaught skills instantly and without help, a process that has been referred to as contingency adduction (Andronis, Layng, \& Goldiamond, 1998; Johnson \& Layng, 1996). These functional criteria represent an important step towards defining fluency objectively.

Recent behavioral training models, such as the Morningside Model of Generative Instruction (Johnson \& Layng, 1994), have combined the best features of PI, PSI and PT into one model, with an emphasis on high rates of responding and fluency. Literature in this area has spurred discussion and generated procedures to develop fluency. Some of these procedures, however, are open to further elaboration and experimentation.

\section{Fluency procedures}

In a series of recent publications, Binder (1996), Lindsley (1996a), and Johnson and Layng (1996) discussed the advantages of fluency measures. They trace the origins of fluency to the methodology of free-operant conditioning and extol the benefits of free- 
operant methods. These methods are contrasted with controlled-operant or discrete-trials methods. Ferster (1953) initially distinguished between methods that allowed learners to respond more than once to each discriminative stimulus, the free-operant, from those that require a single response to each stimulus, the controlled-operant. For example in mathematics, free-operant training might involve writing the same math fact repeatedly but a controlled-operant procedure might present a series of math problems, requiring an answer to each problem.

Even though this basic distinction may still be pertinent to educational tasks (Lindsley, 1996), other methods for presenting these tasks have evolved. For example, Lindsley, a long time advocate of free-operant methods, encourages the use of a procedure called "Say All Fast A Minute Each Day Shuffled" or SAFMEDS. SAFMEDS involves using flash cards for practicing learning material to fluency. Students read all the cards out loud, fast, every day a minute at a time, and then shuffle them between sessions. This method fits Ferster's (1953) definition of the controlled-operant. Similarly, Johnson and Layng (1996) suggest that "most real-world examples of freeoperant performance retain the feature of free responding, but with each response comes a new or different discriminative stimulus" (p. 282). According to Johnson and Layng, the critical problem with controlled-operant procedures, which they redefine as discrete trial procedures, is that the experimenter controls the time between presentations of the discriminative stimuli $\left(\mathrm{S}^{\mathrm{D}}\right)$. This would typically hinder the student from achieving high rates, a prerequisite for achieving fluency. 
A consideration of these distinctions between free-operant and controlled-operant procedures yields a number of methods for presenting tasks to students, all of which allow one response to each $S^{\mathrm{D}}$. The difference between approaches is how trials (i.e., presentations of a new $S^{\mathrm{D}}$ ) are separated. One approach, which has been called a freeoperant, though technically it is not, presents multiple trials concurrently in a single workspace with no experimenter imposed inter-trial intervals (ITIs). For example, a sheet of paper or a computer screen with multiple math problems is presented to the student. A second approach presents one trial at a time, requires a response before presentation of the next trial, and imposes an ITI between trials. ITIs can vary from those that are long enough to decrease the rate of subject's responding, to minimum or $0 \mathrm{~s}$ ITIs programmed so that even the fastest subject does not have to wait to respond to each trial.

Although none of these procedures meet the definition of the free-operant, Binder (1996), Lindsley (1996), and Johnson \& Layng (1996) all advocated procedures that they identify with the free-operant. The defining feature of these procedures seems to be the removal of experimenter or teacher control over the presentation of trials. They recommend using either flash-card procedures (SAFMEDS) that the students manipulate themselves or a procedure that presents multiple tasks on a single sheet of paper. Their rational for this preference is that experimenter or teacher controlled presentation of trials may impose ceilings on the subjects' performance. When teacher or experimenter controlled presentations are slow enough to impose time restrictions, then the amount a 
student can practice per unit of time might be effected. Thus, given that learning is directly related to practice (LaBerge \& Samuels, 1974; Stevens \& Savin, 1962) methods that impose time restrictions will be less effective than those that do not.

It is unclear, however, whether presenting tasks or trials one at a time necessarily imposes ceilings upon performance. When the teaching materials and equipment used are sophisticated enough to allow changes of the discriminative stimuli that are rapid enough to be faster than any subject could possibly respond, the trial procedures should not slow learners' performance. Consequently it may not be the trial procedure per se that causes the ceiling effects, but rather the inadequacy of teaching equipment or techniques (e.g., slow computers, inadequate software, or manually-controlled trials) that increases ITIs and decreases time on task.

It is surprising that in spite of extensive discussions favoring training methods where experimenter imposed time constraints are eliminated, their effectiveness over other methods has never been tested systematically. In view of the rapid developments in computer technology (advanced hardware and software), it would be unwise to exclude some variations of controlled-operant training methods unless data from carefully implemented experiments suggest that they are not adequate. Thus, the purpose of this study was to evaluate the difference between various methods for presenting learning tasks to subjects with regard to their effectiveness for establishing fluent behavior. Specifically, this study compared the effects of three task-presentation procedures on three main fluency outcomes, retention, application, and adduction. One procedure, called No ITIs, will present multiple 
tasks simultaneously on a computer screen after subjects have demonstrated accurate responding to individually-presented tasks. Subjects will be trained using this presentation mode until they reach a rate criterion that has been correlated with retention and application. Munson (1998) tested terminal rate-training rates of 25, 30, 35, and 40 responses per minute and found that all but the first one (25) predicted acceptable performance on tests of retention, endurance, stability, and application. Therefore, the rate of 30 responses per minute was selected as a rate criterion in this experiment. A second procedure, called $0 \mathrm{~s}$ ITIs, will present individual tasks with a zero second ITI after subjects have demonstrated accurate responding. Subjects will be trained using 0s ITIs until they reach the rate criterion used with the first procedure. The third procedure, called 1.5s ITIs, is similar to the second, but will impose a long enough ITI between tasks to effectively slow responding of all subjects. Subjects will be trained using 1.5s ITIs until a criterion for the number of tasks completed correctly is reached. The criterion number of tasks will equal the number of tasks required by subjects using the 0 s ITIs procedure to reach the rate criterion. These three procedures manipulate elements of experimenter imposed delays between trials that have been hypothesized to affect performance.

\section{Method}

\section{$\underline{\text { Subjects }}$}

Thirty-one West Virginia University undergraduates served as subjects. They were recruited through an advertisement (see Appendix A) posted on the Psychology Department's subject recruitment board. The subjects were randomly selected from those 
who signed up for the experiment. Potential subjects were given a short paper and pencil test consisting of translating 10 binary numbers into decimal equivalent (see Appendix B). None of the subjects responded accurately to any of the binary numbers on the subject selection test. All subjects had completed either College Algebra (Math 3) or Finite Mathematics (Math 28) and were not Computer Science majors. Subjects were randomly assigned to experimental conditions and were asked to participate four to five days a week for one hour each day. All subjects were required to read and sign an Informed Consent Form prior to their participation (see Appendix C and Appendix D). One of 31 subjects failed to show acceptable progress during training, and was therefore excused from the study.

\section{$\underline{\text { Settings and apparatus }}$}

Experimental sessions were conducted in $2.2 \mathrm{~m}$ by $1.8 \mathrm{~m}$ room equipped with a table, a chair and the apparatus. Experiment sessions were run on an Intel-based 486 microcomputer running at $33 \mathrm{MHz}$ with $8 \mathrm{MB}$ of random access memory (RAM), a 14" color SVGA computer monitor, and a keyboard. The computer programs that controlled experimental sessions were programmed in MS-DOS ${ }^{\circledR}$ versions of the Turbo Pascal and $\mathrm{C}$ programming languages. The computer was used to control experimental sessions and collect data. The subjects made their responses through a microphone with noise-canceling and directional audio properties (Shure microphone, model SM-10A), that was connected to the computer's motherboard by an IBM Multimedia Audio Capture and Playback Adapter (M-ACPA) audio board. 


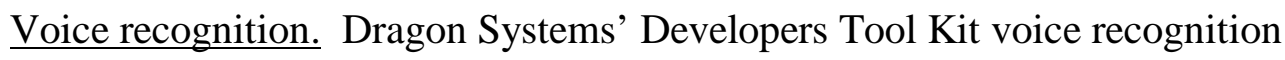
software was used. This software can be programmed to accompany any $\mathrm{C}$ or $\mathrm{C}++$ computer program. When subjects emit a vocal utterance above $25 \mathrm{~dB}$, the computer system receives an analog signal from the microphone, converts it to digital format in the M-ACPA audio board, and sends a digital signal to a memory-resident speech driver. The speech driver compares the digitized pattern with word patterns stored in memory from a particular vocabulary of utterances sampled from the subject, then sends a representation of the word spoken (if recognized) to the main program running the experiment. The digitized patterns are sent to the speech driver throughout an utterance so that processing and recognition can occur simultaneously without waiting for the end of an utterance. The speech driver requires a minimum of $100 \mathrm{~ms}$ between utterances. This procedure allowed voice input to be treated similarly to keyboard input without appreciably slowing down the main computer program.

Calibration. The Dragon System speech driver was trained to recognize (digitize) speech from each individual subject by having subjects repeat each word to be used. A 54 word vocabulary was trained, i.e., the words "zero" through "fifty-one" "stop" and "go". The speech driver's confidence level was also used to calibrate the voice recognition equipment. Subjects repeated each word a minimum of three times or until the speech driver's confidence level was above $90 \%$ for three consecutive utterances. The calibration took 5-10 minutes to complete, and ensured the accuracy of the voice recognition apparatus. In addition, for increased accuracy of the voice recognition 
apparatus subjects re-calibrated the speech driver before each experimental session by saying each word in the vocabulary at least once or until the speech driver's confidence level was above $90 \%$.

\section{$\underline{\text { General outline of experiment }}$}

The experimental phases are shown in Table 1. After pre-training and the first test, all subjects were trained to translate binary numbers to decimal numbers to at least $85 \%$ accuracy (Howell \& Lorson-Howell, 1990) using the same computer based training. After a second test, the three different methods under investigation were used to provide subjects with additional practice. Subsequent tests occurred immediately after subjects had met rate or practice criteria and after two weeks without practice.

\section{$\underline{\text { Procedures }}$}

Testing. All eligible subjects were tested four times during the study. The first test was administered after subjects had completed pre-training, the second test was administered after they completed accuracy training, the third was administered at the completion of rate training, and the fourth about two weeks after training. All test versions were equivalent, i.e., the problems required the same computational skills, but were different in terms of the order of binary used. Prior to the administration of the first test, the following instructions were delivered verbally by the experimenter: "You will now be tested on what you already know about binary numbers. Read the instructions on the screen carefully and the say "go" when you are ready. Try to answer as many questions as you can from each of the six testing screens, using what you have already 


\section{Table 1}

Experimental Phases for All Training Conditions and All Subjects in the Experiment.

\section{Experimental phases}

I. Subject Selection Test

II. Pre-training

III. Testing: Pretest

IV. Training: to $85 \%$ accuracy

V. Testing: Post Accuracy

VI. Rate Training or Practice (0s ITIs; 1.5s ITIs; or No ITIs)

VII. Testing: Post Rate

VIII. Testing: Retention 
learned. You may not be able to answer many of the questions, but try your best". Identical verbal instructions were delivered prior to administration of all tests with the exception of the last sentence. The first test (after pre- and vocabulary training) was administered towards the end of the first experimental session. All other tests were given at the beginning of a session, i.e., subject would reach a criterion, the session was terminated, and a test administered at the beginning of next session.

Three types of tasks were tested on each of the four tests, using two different methods of presenting the problems on the screen, a Trial method and a Multi-trial method. Therefore, each test consisted of 6 different sections ( 3 types of tasks by 2 modes of screen presentation). The Trial method for presenting the testing material presented one stimulus on the screen at a time with the next stimulus presented after a response was made with a 0s ITI. The Multi-trial method presented 50 stimuli on the screen at a time and subjects proceeded by responding from left to right, as if reading a book. The order in which these methods were used was counterbalanced across subjects.

The first task subjects completed involved translating the five digit binary numbers that they learned during training. They were required to translate the binary numbers into decimal numbers $(0-31)$ in a one-minute timing. When the Trial presentation mode was used, subjects received the following instructions before being presented with the test: "Your task is to translate a series of 5-digit BINARY numbers into DECIMAL numbers as FAST as you can. You will have ONE MINUTE to do so. The numbers will be presented on the screen ONE AT A TIME. For example, if you see 
'00000', you should say 'zero'. Please say the word 'GO' to start'. When Multi-trial presentations were used, subjects were presented with different instructions prior to being tested: "Your task is to translate a series of 5-digit BINARY numbers into DECIMAL numbers as FAST as you can. You will have ONE MINUTE to do so. FIFTY numbers will be presented on the screen at a time. Translate them from left to right, as if reading a book. The number you are working on will be presented in WHITE. For example, if you see '00000', you should say 'zero'. Please say the word 'GO' to start'.

The second task required subjects to translate six digit binary numbers that they had not been trained to translate into the decimal numbers 32 to 51 in one-minute timings. When the Trial presentation mode was used, subjects received the instructions: "Your task is to translate a series of SIX-digit BINARY numbers into DECIMAL numbers as FAST as you can. You will have ONE MINUTE to do so. The numbers will be presented on the screen ONE AT A TIME. For example, if you see '000000', you should say 'zero'. Please say the word 'GO' to start." Before the Multi-trial presentation mode, subjects received the same instructions except the sentences: "FIFTY numbers will be presented on the screen at a time. Translate them from left to right, as if reading a book. The number you are working on will be presented in WHITE." was substituted for the sentence: "The numbers will be presented on the screen ONE AT A TIME."

Third, subjects were required to solve simple arithmetic problems presented in five digit binary numbers, giving the answers in decimal numbers $(0-51)$, in one-minute timings. Before the Trial presentation mode was used, subjects were presented with the 
following instructions: "Your task is to solve a series of MATH PROBLEMS presented in BINARY numbers and give the answer in DECIMAL numbers. Do this as FAST as you can. You will have ONE MINUTE. The problems will be presented on the screen ONE AT A TIME. Some of the problems involve ADDITION and some SUBTRACTION. For example, if you see '00001+00001', you should say 'two'. Or, if you see '00010-00001', you should say 'one'. Please say the word 'GO' to start'. Prior to the Multi-trial presentation mode the same instructions were read to subjects, except that the sentence: "The problems will be presented on the screen ONE AT A TIME" was replaced by the following: "FIFTY problems will be presented on the screen at a time. Proceed from left to right, as if reading a book. The problem you are working on will be presented in WHITE." Only 49 math problems, not 50, were presented on the screen, but for simplification purposes the subject instructions were kept simple and as similar to the instructions for the other testing tasks as possible.

Subjects were presented with these six testing tasks sequentially and data were collected on accuracy of responding (\% correct), latency of responding to each question, and rate of responding.

Pre-training. The experimenter read the following instructions to all subjects: "During this experiment you will be trained to recognize and translate binary numbers into decimal numbers, both accurately and fast. Between training phases, you will be tested on your performance. Most training and testing will be conducted on a computer. For training and testing you will be presented with binary numbers on the computer 
screen. Before each training or testing phase, you will also be presented with specific instruction about what is expected of you. Read the instruction carefully and ask the experimenter if something is unclear. In general, your task will be to translate the binary numbers into their decimal equivalents. For each correct translation, i.e., each correct response you make, you will get one point and you will accumulate these points throughout the experiment. Each point is worth one half cent. You will earn the most money by responding accurately and fast. The more accurate you are and the faster you go, the more money you will earn. Remember, that there is no penalty for incorrect answers, so guessing may be appropriate in some cases". Then, subjects read a short paper and pencil program explaining how to translate binary numbers into decimal numbers (see Appendix E). Prior to going through the program the following instructions were delivered verbally by the experimenter: "Now you will go through instructions explaining how to translate binary into decimal numbers. Read the instruction carefully and answer the questions being asked. The correct answers are provided (experimenter points), but do not check them until you have tried yourself; cover the answers with a piece of paper. At the end of the instructions you will be asked to translate a few binary numbers into decimals. Check your answers with the experimenter". The final question of the program asked subjects to translate 5 binary numbers to decimal numbers. If they failed to translate all five correctly, they were asked to read through the instruction again and answer the questions that they missed on their 
previous attempt. All subjects translated all five binary number correctly by the second attempt.

Vocabulary Training. Following pre-training of binary numbers the speechdriver was calibrated (as described previously). The experimenter read the following instructions: "Now the computer has to be trained to recognize your speech. A vocabulary of 52 numbers and 2 words will be trained. This will take approximately 15 minutes and requires you to repeat the same word a number of times. The first words you may have to repeat very often but as the computer starts recognizing your speech, fewer repetitions are needed. Be careful to say only the word the computer asks for. After training, your vocabulary will be re-calibrated by having you go once more through it; usually only once per each word."

Accuracy training. Following pre-training and vocabulary training (calibration), subjects read the following instructions presented on the computer monitor: "Your task is to translate a series of BINARY numbers into DECIMAL numbers and SAY the answer. If your answer is CORRECT you will hear a HIGH tone and a point will be added to your score. If your answer is INCORRECT you will hear a LOW tone and you will be asked to try again. If you answer incorrectly for the second time, the correct answer will be given. No points will be given for incorrect answers nor correct second attempts. For example, if you see '00000', you should say 'ZERO'. Please say the word 'GO' to start'. The binary numbers were presented in a random sequence, one at a time, centered on the computer monitor. Subjects responded by saying the corresponding decimal number to 
each binary number. Subjects received feedback after each response. If a response was correct, i.e., the word spoken by the subject matched the decimal equivalent of the binary number on the screen, a $200 \mathrm{~Hz}$ tone was sounded and a point was added to a point counter displayed on the screen and the next trial appeared immediately on the screen. If the response was incorrect, i.e., the vocal utterance did not match the decimal equivalent of the binary number, a computerized $800 \mathrm{~Hz}$ tone, and the message, "Incorrect, please try again" occurred. The feedback for correct and incorrect responses during correction trials was the same as during the first presentation, but subjects did not gain points for correct answers. In addition, if subjects respond incorrectly to a correction trial the statement "Incorrect. The correct answer was XX." was flashed on the center of the screen above the target stimulus for two seconds, after which the next binary number was presented.

Subjects responded to three blocks of 20 trials, receiving feedback on their accuracy after each block of trials. All subjects achieved $85 \%$ accuracy by the third block of 20 trials, after which they received the second test.

Condition I: 0s ITIs. Before undergoing pre-training 10 subjects were randomly selected from a pool of 30 subjects to receive Condition I, 0s ITI's training. Subjects received pre-training and accuracy training and then, before initiating rate training, the experimenter read the following instructions: "During this training phase you will be trained to translate binary numbers accurately and fast in 1-minute timings. Read the instructions carefully and let the experimenter know if you have any questions. If the 
feedback at the end of each timing tells you to be faster or more accurate or both, press F3 and ENTER to start the next session. Otherwise, call the experimenter. REMEMBER, that the faster you go and the more accurate you are, the more you will earn". These instructions were consistent across all conditions of the experiment. Then the subjects were presented with the following instructions on the computer monitor: "You will now be presented with a series of BINARY numbers. Your task is to translate them into DECIMAL numbers and SAY the answer as FAST as you can without losing ACCURACY. You will have ONE MINUTE to do so. Each correct answer is worth ONE POINT. However, you will only receive feedback on your performance at the end of each ONE-MINUTE timing. For example, if you see '00000', you should say 'ZERO'. Please say the word 'GO' to start". Subjects were exposed to series of 1 minute-timings in which feedback for each trial was removed. After each response a $0 \mathrm{~s}$ ITI was programmed. At the end of the one-minute timing, subjects received feedback on the number of trials attempted, number of correct responses, number of incorrect responses, percentage of correct responses, and the number of total points accumulated throughout the experiment. One-minute timings continued until subjects reached a rate of 30 correct responses per minute for two one-minute timings while maintaining $85 \%$ accuracy. These criteria have been correlated with retention and application of binary numbers that reflects fluent performance (Munson, 1998).

Additional feedback was provided after each timing dependent on subject's performance. If subjects maintained $85 \%$ accuracy, but had not reached the rate 
criterion, the instructions "You need to be faster. Try again." appeared in the middle of the screen. If subjects reached the rate criterion, but were below $85 \%$ accuracy, the instructions "You need to be more accurate. Try Again." appeared on the screen. When rate of responding was below the rate criterion and accuracy was less than $85 \%$, the instruction "You have to go faster and be more accurate." appeared on the screen. When subjects responded with $85 \%$ accuracy or better and above rate criterion for the first time, they received the message "Well done! Please get the experimenter". They were then told that "You are doing very well, but you still have to go through a few more timings". After the second timing that subjects met both rate and accuracy criteria, training was completed and subjects were tested for the third time.

Condition II: $1.5 \mathrm{~s}$ ITIs. The rate-training procedure and instructions were exactly the same as in Condition I with the addition of $1.5 \mathrm{~s}$ blackout interval between trials. The number of trials subjects completed was yoked to the number of trials needed to reach the rate criterion for subjects in the 0s ITIs training condition. Yoking was accomplished by the following procedures: A subject was randomly selected from the subject pool, assigned to the $1.5 \mathrm{~s}$ ITIs condition, and yoked to a subject in the 0s ITIs condition. At the end of each one-minute timing subjects received feedback on their accuracy. When their accuracy was above the $85 \%$ criterion they received the following instruction "Well done. Try again". However, if accuracy fell below $85 \%$, subjects received the instruction "You need to be more accurate. Try again". When subjects had completed the predetermined (yoked) number of trials, the message "Well done! Please get the 
experimenter" was flashed on the screen and the one-minute timing was terminated. Subjects were then tested for the third time.

Condition III: No ITIs. Before undergoing pre-training 10 subjects were randomly selected from a pool of 30 subjects to receive No ITI's training. Subjects received the same pre-training and accuracy training as in first two training conditions, 0s and 1.5s ITIs. Then, before initiating rate training the following instructions were presented on the computer monitor: "You will now be presented with 50 BINARY numbers on the computer monitor before you. Your task is to translate them into DECIMAL numbers and SAY the answer as FAST as you can without losing ACCURACY. You will have ONE MINUTE to do so. Each correct answer is worth ONE POINT. However, you will only receive feedback on your performance at the end of each ONE-MINUTE timing. Proceed by translating numbers from left to right as if reading a book. The number you are working on will be presented in WHITE. For example, if you see '00000', you should say 'ZERO'. Please say the word 'GO' to start'. Fifty binary numbers then appeared on the computer screen at a time. Subjects responded to as many of the problems on the computer screen as possible in one minute. Responses were made in the same way as in the other training conditions. After each one-minute timing, subjects received feedback on the accuracy and rate of their performance, as in 0s ITIs training. Training proceeded until rate of 30 responses per minute and $85 \%$ accuracy criteria were met, after which subjects were tested. 
Payment Contingencies. Subjects earned half a cent per each correct response during accuracy training, rate training, and testing. In addition to performance based earnings, subjects earned an attendance bonus of $\$ 6$ for not missing any sessions without notifying the experimenter. If subjects failed to attend a scheduled appointment without notifying the experimenter in advance, they lost their attendance bonus. Subjects were also eligible to earn bonus points for courses that allowed credit for participation in research. All earnings were paid at the end of subjects' participation.

Results

\section{Pre-training}

All subjects completed the programmed instruction on binary numbers within 20 minutes. No subject made an error on the first four frames of the program. Seven subjects made errors on the final frame, which involved translating five binary numbers into decimals. Six subjects made one error and one made two errors. All subjects corrected the errors on their second attempt to achieve $100 \%$ accuracy on the final question. Two of these subjects were in the 0s ITIs group, and five in 1.5s ITIs group, including the one that made two errors. None of the subjects in the No ITIs group made an error during the pretest. Most errors were simple addition or multiplication errors that were quickly resolved.

Accuracy training

All thirty subjects achieved $85 \%$ accuracy or better by their third block of accuracy training trials and the average accuracy across subjects was 90, 96, and $96 \%$ 
for the first, second and third blocks of trials, respectively. There were no differences in performance between conditions for any of the three accuracy training blocks, $\underline{\mathrm{F}}(2,27)=$ $1.22, \underline{p}>.05, \underline{F}(2,27)=.927, \underline{p}>.05$, and $\underline{F}(2,27)=.339, \underline{p}>.05$ for blocks one, two and three, respectively.

$\underline{\text { Rate Training }}$

As can be seen in the top panel of Table 2, subjects who received No ITIs training spent less time in rate training than subjects who were trained using $0 \mathrm{~s}$ and $1.5 \mathrm{~s}$ ITIs, with an average of 29 one-minute timings needed to reach criterion. Subjects who received 0s ITIs training also spent less time in rate training, 60 one-minute timings, than the $1.5 \mathrm{~s}$ ITIs subjects, who went through 94 one-minute timings. A Scheffe test with an alpha level of .05 was use for post hoc comparisons. The test showed that these differences were significant, $\underline{\mathrm{F}}(2,27)=16.21, \underline{\mathrm{p}}<.0001$. The average number of trials required to achieve rate criterion was also significantly higher for the 0 and $1.5 \mathrm{~s}$ ITIs conditions when compared to the No ITIs, or 1423, 1422 and 696 trials, respectively ( $\underline{F}$ $(2,27)=6.83, \mathrm{p}=.004)$. There was no difference between 0 s and $1.5 \mathrm{~s}$ ITIs subjects. Differences in the accuracy of responding were not significant between conditions $(\underline{\mathrm{F}}(2$, $27)=1.90, \underline{p}>.05)$ with an average accuracy of $91 \%$ for 0 s ITIs, $91 \%$ for 1.5 s ITIs and 94\% No ITIs. Consistent with the differences in total numbers of trials to criteria, subjects who received ITI training ( 0 s and $1.5 \mathrm{~s}$ ITIs), also made significantly more correct responses than subjects who received No ITIs training, $\underline{F}(2,27)=6.36, \underline{p}=.0054$ and more incorrect responses, $\underline{\mathrm{F}}(2,27)=5.11, \underline{\mathrm{p}}=.013$. The 0 s ITIs subjects made an 
average of 1314 correct and 108 incorrect responses and the 1.5s ITIs subjects made 1306 correct and 112 incorrect responses on the average, whereas the No ITIs subjects made an average of 652 correct and 44 incorrect responses.

Analyses of responding per one-minute timing during rate training are presented in the middle panel of Table 2. Even though the accuracy of responding was similar across conditions, the $1.5 \mathrm{~s}$ ITIs subjects made fewer correct responses per one-minute timing than subjects undergoing 0s ITIs and No ITIs training, an average of 14 versus 22 and $23(\underline{F}(2,27)=81.47, \underline{p}<.001)$. Subjects in general made very few incorrect responses and there were no differences between groups, $\underline{F}(2,27)=2.25, \underline{p}>.05$. The total number of responses per one-minute timing was also lower for subjects undergoing 1.5s ITIs training than for subjects undergoing 0 s and No ITIs training, an average of 15 versus 24 and $25, \underline{F}(2,27)=112.47, \underline{p}<.001$. The average rate of responding over the last five one-minute timings was also significantly lower for subjects who underwent 1.5s ITI training than for the 0 s and No ITI training subjects, 171 responses versus 29 responses per minute for both the 0 s and No ITIs groups, $(\underline{F}(2,27)=304.89, \underline{p}<.001)$. The bottom panel of Table 2 presents other rate training data of interest. There were no differences between the three conditions with respect to the confidence of the computer recognizing the subjects' utterances $(\underline{F}(2,27)=1.78, \underline{p}>.05)$, nor were there any

1 Because subjects in the $1.5 \mathrm{~s}$ ITIs training condition were yoked to subjects in the 0s ITIs condition, they were stopped without completing the last one-minute timing if they had met their practice criterion. Therefore, the last one-minute timing was not used in calculating the average rate of the last five timings for these subjects. 


\section{Table 2}

Mean Performance Scores of Subjects in All Training Conditions During Rate Training.

Standard deviations are presented within parenthesis.

\begin{tabular}{|c|c|c|c|c|c|}
\hline & \# of 1-min & \# of trials & Accuracy & \# of correct & \# of incorrect \\
\hline & timings & $(\%)$ & trials & trials & \\
\hline Os ITIs & $60(24)$ & $1423(582)$ & $91(3.6)$ & $1314(545)$ & $108(61)$ \\
\hline $1.5 \mathrm{~s}$ ITIs & $94(33)$ & $1422(575)$ & $91(4.1)$ & $1306(541)$ & $112(62)$ \\
\hline \multirow[t]{3}{*}{ No ITIs } & $29(14)$ & $696(320)$ & $94(3.1)$ & $625(297)$ & $44(31)$ \\
\hline & Correct trials & Incorrect tr. & Trials per & Rate: Last & \\
\hline & per timing & per timing & timing & 5 timings & \\
\hline Os ITIs & $22(1.4)$ & $2(0.6)$ & $24(1.2)$ & $29(1.7)$ & \\
\hline $1.5 \mathrm{~s}$ ITIs & $14(0.8)$ & $1(0.6)$ & $15(0.9)$ & $17(1.2)$ & \\
\hline \multirow[t]{3}{*}{ No ITIs } & $23(2.6)$ & $1(0.7)$ & $25(2.3)$ & $29(0.8)$ & \\
\hline & Confidence of & \multicolumn{2}{|c|}{ Latency of } & \multicolumn{2}{|l|}{ Duration of } \\
\hline & recognition & \multicolumn{2}{|c|}{ responding } & utterance & \\
\hline Os ITIs & $90(4.2)$ & \multicolumn{2}{|c|}{$1759(141)$} & 438 (109) & \\
\hline $1.5 \mathrm{~s}$ ITIs & $87(5.4)$ & \multicolumn{2}{|c|}{$1647(205)$} & $434(59)$ & \\
\hline No ITIs & $89(3.2)$ & \multicolumn{2}{|c|}{$1662(258)$} & $505(89)$ & \\
\hline
\end{tabular}


differences in latency of responding $(\underline{\mathrm{F}}(2,27)=0.87, \underline{\mathrm{p}}>.05)$ and utterance duration $(\underline{\mathrm{F}}$ $(2,27)=2.04, \underline{p}>.05)$

Figure 1 captures the primary similarities and differences between training conditions. It shows the change in rate of correct and incorrect responding that occurs as a result of rate training for one representative subject from each of the three conditions. Subjects H07 and H30 were selected because their performance corresponds to closely to their respective the group averages. Subject h12 is shown because it was yoked to H07 for practice. A common characteristic was that the number of incorrect responses decreased slightly throughout training whereas the number of correct responses increases considerably. For the subjects who received 0s and No ITIs training (H07 and H30) the rate of responding increased until they reached the rate criterion. For subject H12, who underwent $1.5 \mathrm{~s}$ ITIs training, the rate increased until about halfway through training and then it stabilized at a fairly constant rate of about 15 responses per minute. There were, however, two notable deviations from the terminal average rate for the $\mathrm{H} 12$ during sessions 73 and 98. The first instance was due to computer failure. In session 98 training was terminated about halfway through the last timing when the subject had responded to the same number of trials as H07. Figure 1 also shows that it took subject H30 (No ITIs) less time to reach the rate criterion than the subject trained with 0s ITIs. Additionally because $\mathrm{H} 12$ responded at a lower rate, it took her more sessions to complete the same number of trials as the subject in the 0s ITIs condition. 
Figure 1. Correct and incorrect rate of responding per 1-minute timings as a function of training (1-minute timings) for representative subjects, $\mathrm{H} 07, \mathrm{H} 12$, and $\mathrm{H} 30$, from each training condition, $0 \mathrm{~s}, 1.5 \mathrm{~s}$, and No ITIs. H12 was yoked to $\mathrm{H} 07$ for practice. The circles represent correct responding and the triangles incorrect responding per 1-minute timings. 
Number of trials
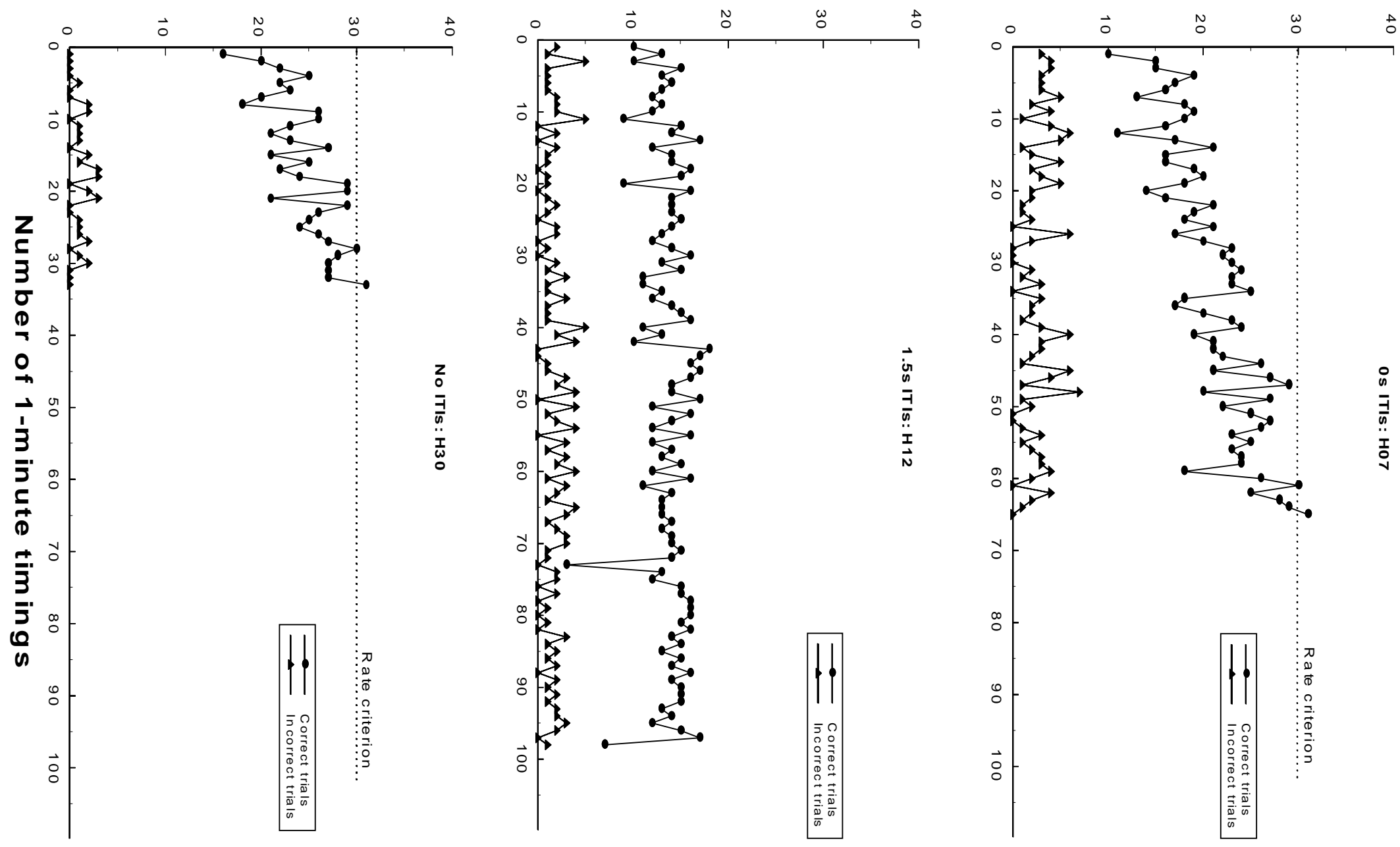


\section{Test performance}

Accuracy. There were no systematic differences between the three conditions on any of the six testing components. In addition, there were no significant differences in accuracy related to the order of Multi-trial and Trial methods of presentation. Therefore, the data were collapsed across conditions and order of presentation methods. Figure 2 shows the mean percent accuracy for each of the six sub-components of each test averaged across the three training conditions. The differences between the four testing administrations were analyzed using t-tests for paired comparisons, an appropriate statistic for within-subject comparisons. The increase in accuracy between the pretest and the post-accuracy test was significant for each sub-component test. For Trained:Trials the mean accuracy increased from $54 \%$ to $84 \%, \underline{t}(28)=-4.83, \underline{p}<.001$. For Trained: Multi-trials the mean accuracy increased from 58\% to 91\%, $\underline{\mathrm{t}}(28)=-5.17, \underline{\mathrm{p}}$ $<.001$. For Untrained: Trials the mean accuracy increased from $53 \%$ to $77 \%, \underline{t}(28)=-$ $3.16, \underline{p}<.001$. For Untrained: Multi-trials the mean accuracy increased from $48 \%$ to $78 \%, \underline{\mathrm{t}}(28)=-4.07, \mathrm{p}<.001$. For Math: Trials the mean accuracy increased from $30 \%$ to $70 \%, \underline{t}(28)=-5.18, \underline{p}<.001$. And For Math: Multi-trials the accuracy increased from $31 \%$ to $61 \%, \underline{\mathrm{t}}(27)=-3.50, \underline{\mathrm{p}}=.002$. There also was a significant increase in accuracy after rate training for two components, i.e., Trained: Trials and Math: Multi-trials, but it did not change for the other four components. The increase for Trained: Trials was from $84 \%$ to $92 \%, \underline{\mathrm{t}}(28)=-2.11, \underline{\mathrm{p}}=.044$, and the increase for Math: Multi-trials was from $61 \%$ to $80 \%, \underline{t}(27)=-3.73, \underline{p}=.001$. Accuracy did not change for any of the six 
Figure 2. Average accuracy of responding on all tasks across training conditions on Pretests, Post Accuracy, Post Rate, and Retention tests. Circles represent Trials and triangles represent Multi-trial presentation modes. The top panel shows trained binary numbers, the middle panel shows untrained binary numbers, and the bottom shows math problems presented in binary numbers. 


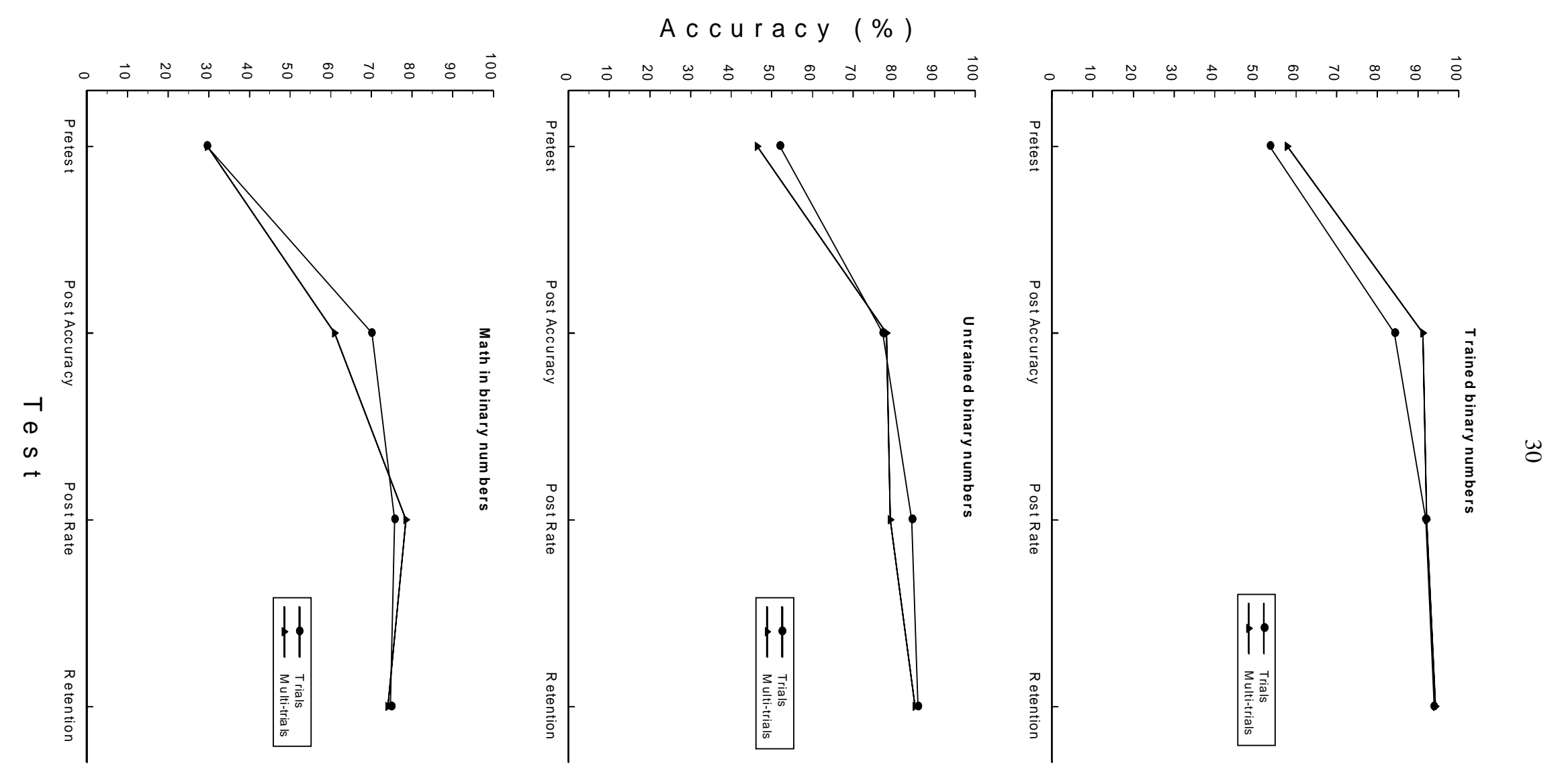


components between the completion of rate training and the retention test. No difference was found between Trial and Multi-trial presentations on any of the tests.

Tables 3 and 4 show a progressively decreasing trend in accuracy of responding across types of tasks. Subjects generally responded more accurately to trained binary numbers than to untrained. Also, they responded more accurately to untrained binary numbers than to math problems presented in binary. As there was no interaction between type of training and type of testing task, data were collapsed across conditions. A repeated measure ANOVA and paired sample t-tests were used for comparing the different types of tasks. The results of the ANOVAs and the simple t-test comparisons are also reported in Tables 3 and 4 . They show that for seven of eight tests there were significant main effects for type of task. Seven of 12 simple comparisons were significant when presented as Trials, and nine of 12 for Multi-trial presentations.

$\underline{\text { Rate of correct responding. Figures 3, 4, and } 5 \text { show the average rate of correct }}$ responding for each sub-component of the tests plotted as a function of condition and training. As between-condition comparisons were planned and between subjects, differences at all tests were evaluated using t-tests for independent samples.

Figure 3 represents testing on trained binary numbers using Trial and Multi-trial presentation modes. The top panel shows performance under the Trial presentation mode. When Trial presentations were used (top panel of Figure 3), 0s ITIs subjects responded correctly to significantly more trials than No ITIs subjects on both the Post Rate and the Retention tests $(\mathrm{t}(18)=2.68, \mathrm{p}=.015, \underline{\mathrm{t}}(18)=3.06, \mathrm{p}=.006)$. In 


\section{Table 3.}

The Mean Accuracy (\%) of Responding for All Subjects to Trained and Untrained Binary Numbers, and Math Problems in Binary on All Tests for Trial Presentations, Including Degrees of Freedom (Df) and F values for a Repeated Measures Analysis of Variance of the Three Tasks. The Lower Panel Shows Simple Comparisons Between

Tasks at All Tests where $\mathrm{T}=$ Trained Trials, $\mathrm{U}=$ Untrained Trials, and $\mathrm{M}=$ Math Trials.

\begin{tabular}{|c|c|c|c|c|}
\hline \multirow[b]{2}{*}{ Type of Task } & \multicolumn{4}{|c|}{ Test } \\
\hline & Pretest & Post Acc. & Post Rate & Retention \\
\hline \multicolumn{5}{|c|}{ Trial presentations: } \\
\hline Trained & 54 & 84 & 92 & 94 \\
\hline Untrained & 51 & 77 & 84 & 86 \\
\hline Math & 29 & 70 & 76 & 74 \\
\hline Df & $(2,58)$ & $(2,56)$ & $(2,56)$ & $(2,56)$ \\
\hline$\underline{F}$ & $5.65 * *$ & 2.44 & $5.37 * *$ & $8.83 * *$ \\
\hline \multicolumn{5}{|c|}{ Simple comparisons: } \\
\hline & $\mathrm{T}>\mathrm{U}$ & $\mathrm{T}>\mathrm{U}$ & $\mathrm{T}>\mathrm{U}$ & $\mathrm{T}>\mathrm{U}^{*}$ \\
\hline & $\mathrm{U}>\mathrm{M}^{*}$ & $\mathrm{U}>\mathrm{M}$ & $\mathrm{U}>\mathrm{M}$ & $\mathrm{U}>\mathrm{M}^{*}$ \\
\hline & $\mathrm{T}>\mathrm{M}^{* *}$ & $\mathrm{~T}>\mathrm{M}^{*}$ & $\mathrm{~T}>\mathrm{M}^{* *}$ & $\mathrm{~T}>\mathrm{M}^{* *}$ \\
\hline \multicolumn{5}{|l|}{$* \mathrm{p}<.05$} \\
\hline$* * \quad \mathrm{p}<.01$ & & & & \\
\hline
\end{tabular}




\section{Table 4.}

The Mean Accuracy (\%) of Responding for All Subjects to Trained and Untrained Binary Numbers, and Math Problems in Binary on All Tests for Multi-trial Presentations, Including Degrees of Freedom (Df) and F values for a Repeated Measures Analysis of Variance of the Three Tasks. The Lower Panel Shows Simple Comparisons Between Tasks at All Tests where $\mathrm{T}=$ Trained Trials, $\mathrm{U}=$ Untrained Trials, and $\mathrm{M}=$ Math Trials.

\begin{tabular}{|c|c|c|c|c|}
\hline \multirow[b]{2}{*}{ Type of Task } & \multicolumn{4}{|c|}{ Test } \\
\hline & Pretest & Post Acc. & Post Rate & Retention \\
\hline \multicolumn{5}{|c|}{ Multi-trial presentations: } \\
\hline Trained & 58 & 91 & 92 & 94 \\
\hline Untrained & 46 & 77 & 79 & 85 \\
\hline Math & 30 & 61 & 79 & 74 \\
\hline Df & $(2,58)$ & $(2,54)$ & $(2,56)$ & $(2,58)$ \\
\hline$\underline{F}$ & $5.67 * *$ & $12,58 * *$ & $4,84^{*}$ & $10.86 * *$ \\
\hline \multicolumn{5}{|c|}{ Simple comparisons: } \\
\hline & $\mathrm{T}>\mathrm{U}$ & $\mathrm{T}>\mathrm{U}^{* *}$ & $\mathrm{~T}>\mathrm{U}^{* *}$ & $\mathrm{~T}>\mathrm{U}^{* *}$ \\
\hline & $\mathrm{U}>\mathrm{M}$ & $\mathrm{U}>\mathrm{M}^{*}$ & $\mathrm{U}>\mathrm{M}$ & $\mathrm{U}>\mathrm{M}^{*}$ \\
\hline & $\mathrm{T}>\mathrm{M}^{* *}$ & $\mathrm{~T}>\mathrm{M}^{* *}$ & $\mathrm{~T}>\mathrm{M}^{* *}$ & $\mathrm{~T}>\mathrm{M}^{* *}$ \\
\hline$* \quad \mathrm{p}<.05$ & & & & \\
\hline$* * \mathrm{p}<.01$ & & & & \\
\hline
\end{tabular}


Figure 3. Average number of correct responses (trials) per minute to trained binary numbers on Pretests, Post Accuracy, Post Rate, and Retention tests for the three training methods. Black bars represent 0s ITIs training, gray bars represent 1.5s ITIs training and white bars represent No ITIs training. The upper panel shows test results when Trial presentations were used and the lower shows results for Multi-trial presentations. The error bars represent standard deviation. 

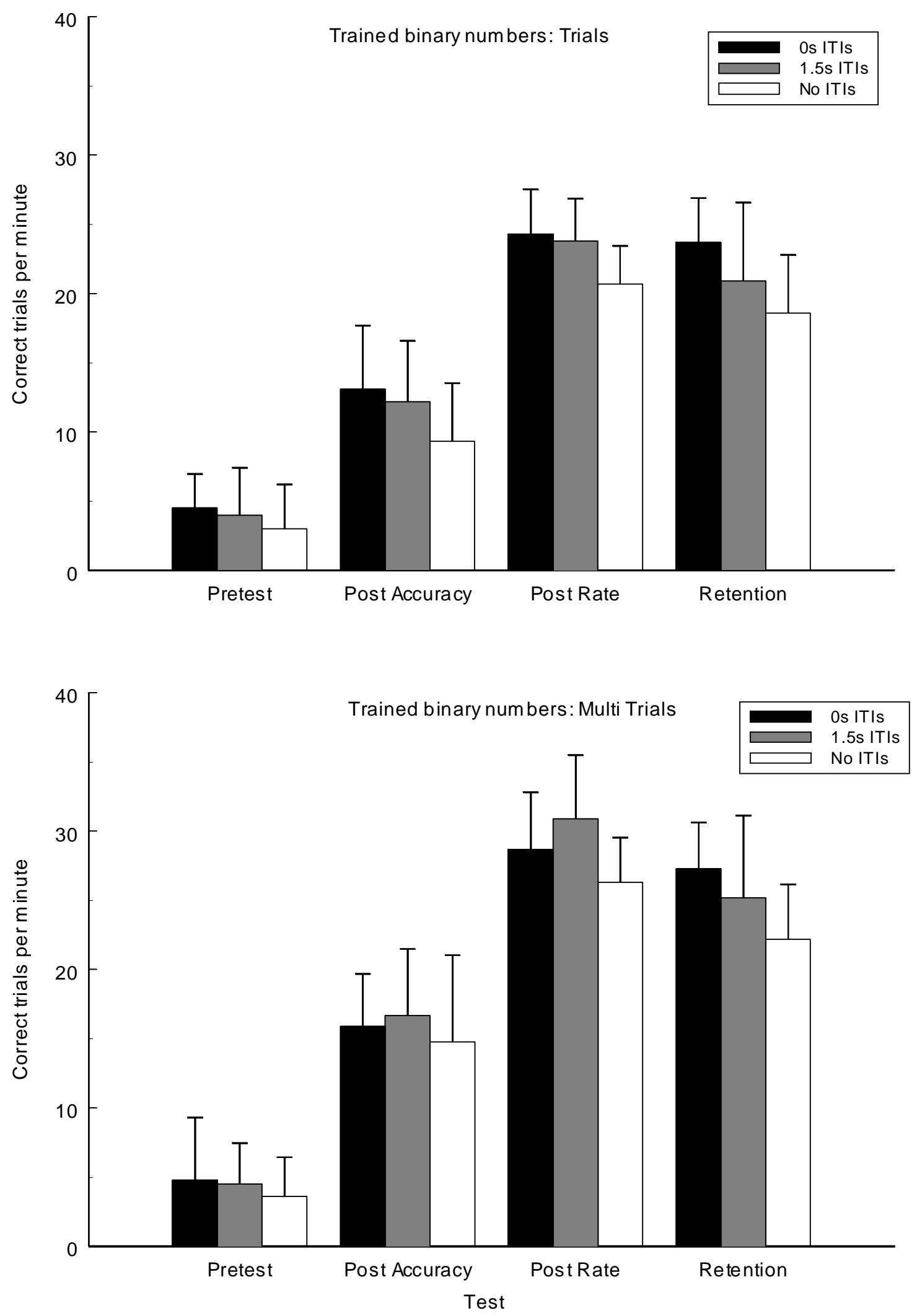
addition, subjects who received $1.5 \mathrm{~s}$ ITIs training performed better than the No ITIs subjects on the Post Rate test $(\mathrm{t}(18)=2.39, \mathrm{p}=.028)$. When Multi-trial presentations were used, $1.5 \mathrm{~s}$ ITIs subjects responded faster than No ITIs subjects on the Post rate test $(\mathrm{t}(18)=2.58, \mathrm{p}=.019)$, and 0s ITI subjects responded faster then No ITIs on the Retention test $(\mathrm{t}(18)=3.13, \underline{\mathrm{p}}=.006)$. No other differences in performance on the four tests were found between the different training methods.

Paired sample t-tests were used to assess any changes in performance throughout training. The top panel of figure 3 shows that when subjects were tested using Trial presentations, all training conditions showed significant increase in number of correct responses to trained binary numbers after Accuracy training $(\underline{t}(9)=-5.16, \underline{p}=.001, \underline{t}(9)$ $=-5.80, \underline{\mathrm{p}}<.001$, and $\underline{\mathrm{t}}(8)=-3.67, \underline{\mathrm{p}}=.006$ for 0s ITIs, $1.5 \mathrm{~s}$ ITIs, and No ITIs, respectively) and a further increase following Rate training $(\mathrm{t}(9)=-6.98, \mathrm{p}<.001, \underline{\mathrm{t}}(9)$ $=-7.59, \underline{\mathrm{p}}<.001$, and $\underline{\mathrm{t}}(8)=-6.13, \underline{\mathrm{p}}<.001$ for 0s ITIs, $1.5 \mathrm{~s}$ ITIs, and No ITIs, respectively). No change in rate of correct responding was found between the Post Rate test and the Retention test (ts $(9)=.45,1.58$, and 1.41 , ps $>.05$ for 0 s ITIs, $1.5 \mathrm{~s}$ ITIs, and No ITIs, respectively). As can be seen in the bottom panel of figure 3, similar results were found when subjects were tested using Multi-trials. The number of correct responses increased for subjects in all conditions after Accuracy training (țs (9) $=-7.29$ and -10.94 , ps $<.001$ for 0s ITIs and 1.5s ITIs, respectively, and $\mathrm{t}(8)=-6.32, \mathrm{p}<.001$ for No ITIs) and also after Rate training (ts $(9)=-7.29,-10.94$, and -6.32 , ps $<.001$ for $0 \mathrm{~s}, 1.5 \mathrm{~s}$, and No ITIs, respectively). On the Retention test, however, subjects who had 
received $1.5 \mathrm{~s}$ ITIs and No ITIs training showed a significant decrease in performance, from 30.9 to 25.2 and 26.3 to 22.2 correct responses, respectively (ts $(9)=3.99$ and 3.95 , $\mathrm{ps}=.003)$. The 0 ITIs subjects' performance did not decrease significantly $(\underline{t}(9)=1.14$, $\mathrm{p}=.285)$ on the retention test.

Figure 3 also indicates that except on the Pretest subjects from all three training conditions performed faster when trained binary numbers were presented using the Multi-trial approach as opposed to the Trial approach. The means for the Trial and Multi-trial test components on trained binary numbers are shown in Table 5. A pairedsample $\mathrm{t}$-test comparing these two test components at all four tests obtained a $\underline{\mathrm{t}}(29)=$ $.73, \underline{p}>.05, \underline{t}(29)=5.02, \underline{p}<.001, \underline{t}(29)=7,91, \underline{p}<.001$, and $\underline{\mathrm{t}}(29)=6.13, \underline{\mathrm{p}}<.001$ for the Pretest, Post Accuracy, Post Rate, and Retention test, respectively.

No differences in latency of responding to trained binary numbers were found between the three training conditions, regardless of presentation mode and test (Pretest through Retention).

The two graphs in figure 4 represent testing on untrained binary numbers using Trial and Multi-trial presentation modes. No statistically significant differences were found between any of the three conditions at any of the four tests for either presentation mode. Subjects in all training conditions, however, showed a significant increase in number of correct responses to untrained binary numbers after Accuracy training for both presentation modes (for Trial presentations: $\underline{\mathrm{t}}(9)=-3.48, \underline{\mathrm{p}}=.007, \underline{\mathrm{t}}(9)=-3.80, \underline{\mathrm{p}}=$ .004 , and $\underline{\mathrm{t}}(8)=-4.26, \underline{\mathrm{p}}=.003$ for 0s ITIs, $1.5 \mathrm{~s}$ ITIs, and No ITIs, respectively, and for 


\section{Table 5}

Mean Number of Correct Responses to Trained Binary Numbers for Trials and Multitrial Presentation Modes on All Tests, Collapsed Across Conditions.

\begin{tabular}{lllll}
\hline Presentation & Pretest & Post & Post & Retention \\
mode & & accuracy & rate & \\
\hline Trial & 3.8 & 11.6 & 22.9 & 21.1 \\
Multi-trial & 4.3 & $15.8^{* *}$ & $28.6^{* *}$ & $27.9^{* *}$ \\
\hline$* \quad \mathrm{p}<.01$ & & & \\
$* * \mathrm{p}<.001$ & & & &
\end{tabular}


Figure 4. Average number of correct responses (trials) per minute to untrained binary numbers on Pretests, Post Accuracy, Post Rate, and Retention tests for the three training methods. Black bars represent 0s ITIs training, gray bars represent $1.5 \mathrm{~s}$ ITIs training, and white bars represent No ITIs training. The upper panel shows testing using Trial presentations and the lower shows Multi-trial presentations. The error bars represent standard deviation. 

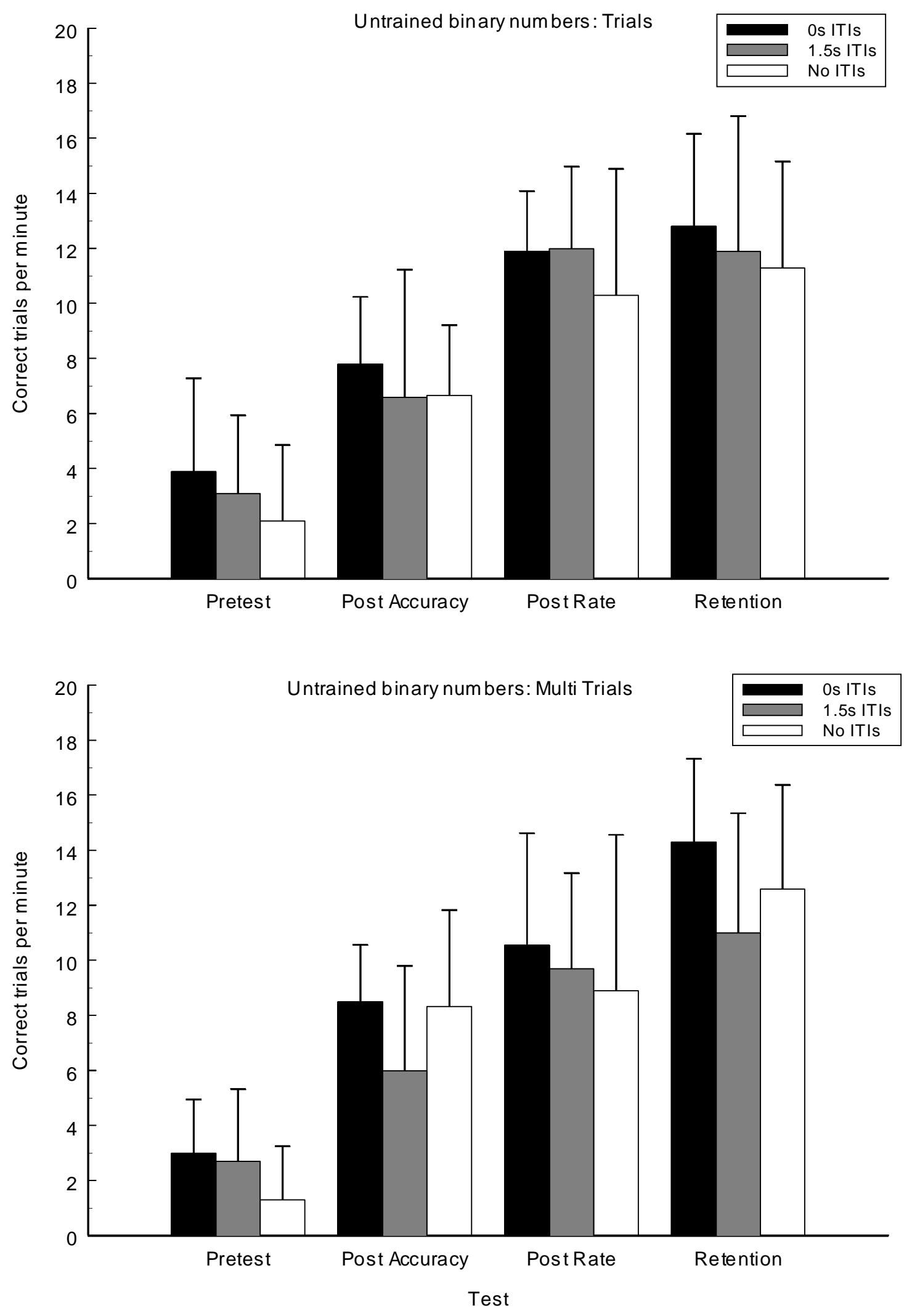
Multi-trials presentations: $(\underline{\mathrm{t}}(9)=-6.71, \underline{\mathrm{p}}<.001, \underline{\mathrm{t}}(9)=-3.19, \underline{\mathrm{p}}=.011$, and $\underline{\mathrm{t}}(8)=-$ $6.20, \underline{p}<.001$ for 0s ITIs, 1.5s ITIs, and No ITIs, respectively). A further increase in rate of correct responding was observed following Rate training for 0s ITIs and 1.5s ITIs, when the Trial presentation mode was used (ts $(9)=-5.07$ and -4.75 respectively, ps $=$ $.001)$, and for $1.5 \mathrm{~s}$ ITIs when the Multi-trial approach was used $(\underline{\mathrm{t}}(9)=-3.51, \underline{\mathrm{p}}=.007)$. On the Retention test, performance remained the same as on the Post Rate test for all three conditions when Trial presentations were used, but the 0s ITIs group and the No ITIs group further improved their performance when Multi-trial presentations were used $(\underline{\mathrm{t}}(8)=-3.02, \underline{\mathrm{p}}=.016$ and $\underline{\mathrm{t}}(9)=-4.13, \underline{\mathrm{p}}=.003$, respectively).

The mean number of correct responses to untrained binary numbers on the Trial and Multi-trial components are shown in Table 6. There were no differences in rate of correct responding between the two presentation modes except on the Post Rate test, where the mean number of correct responses to untrained binary numbers was 11.4 for the Trial presentation mode, and 9.7 on the Multi-trial mode $(\underline{\mathrm{t}}(28)=3.0, \underline{\mathrm{p}}=.006)$.

No differences in latency of responding to untrained binary numbers were found between the three training conditions, regardless of presentation mode and test (Pretest through Retention).

Figure 5 shows the number of correct trials per minute on tests of simple math problems involving addition and subtraction presented in binary numbers using Trial (top panel) and Multi-trial (bottom panel) presentation modes. No differences were 


\section{Table 6}

Mean Number of Correct Responses to Untrained Binary Numbers for Trials and Multitrial Presentation Modes on All Tests, Collapsed Across Conditions.

\begin{tabular}{lllll}
\hline Presentation & Pretest & Post & Post & Retention \\
mode & & accuracy & rate & \\
\hline Trial & 3.0 & 7.0 & 11.4 & 12.0 \\
Multi-trial & 2.3 & 7.6 & $9.7^{*}$ & 12.6 \\
\hline
\end{tabular}

$* \quad \underline{p}<.01$ 
Figure 5. Average number of correct responses (trials) per minute to math problems in presented in binary numbers on Pretests, Post Accuracy, Post Rate, and Retention tests for the three training methods. Black bars represent 0s ITIs training, gray bars represent 1.5s ITIs training, and white bars represent No ITIs training. The upper panel shows testing using Trial presentations and the lower shows Multi-trial presentations. The error bars represent standard deviation. 

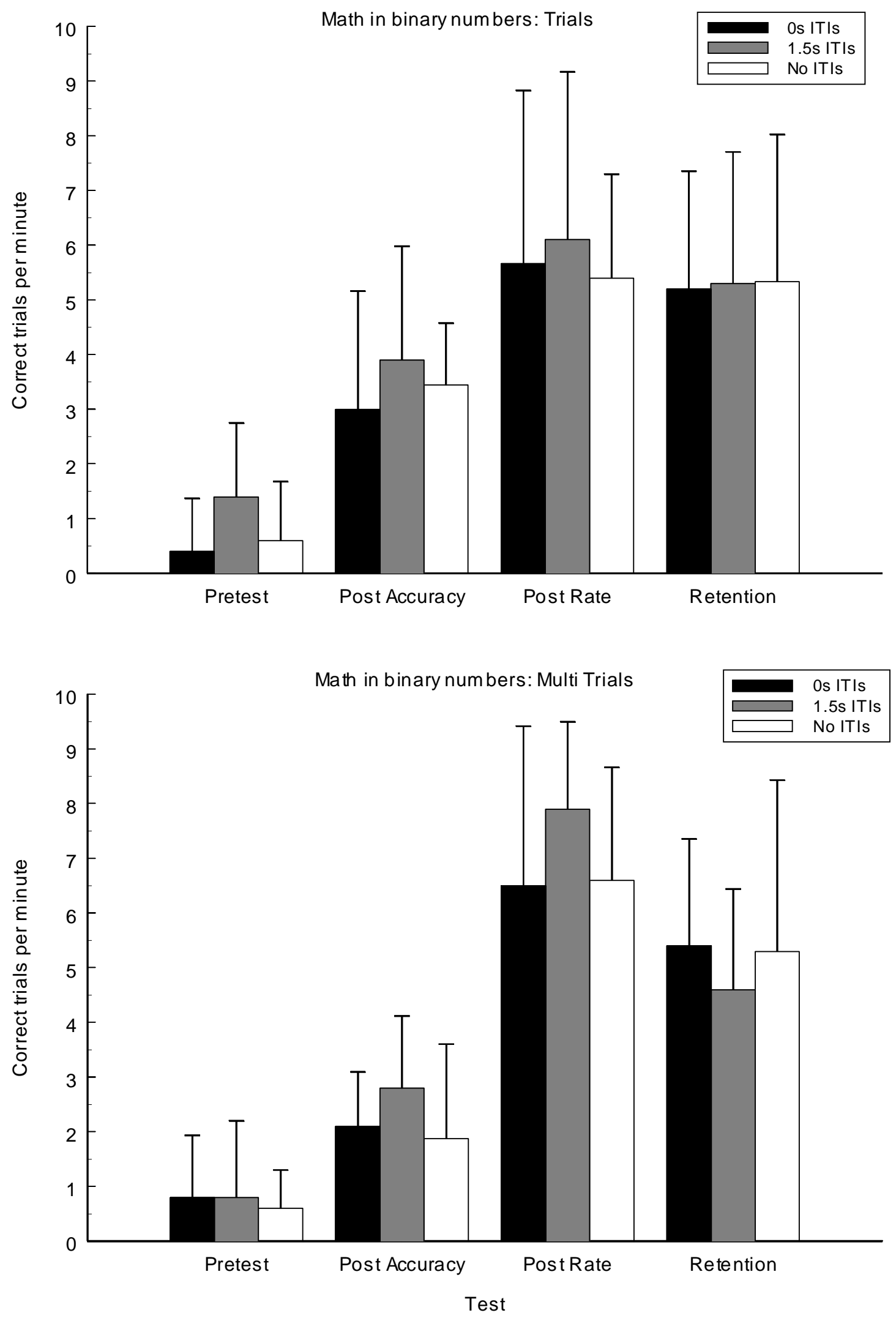
found between any of the three conditions at any of the four tests, regardless of presentation mode (Trial and Multi-trials).

Subjects in all three conditions, however, showed a significant increase in rate of correct responding to math problems after Accuracy training when the math problems were presented using the Trial presentation mode $(\underline{t}(9)=-3.55, \underline{p}=.006, \underline{t}(9)=-4.04, \underline{p}$ $=.003$, and $\underline{\mathrm{t}}(9)=-7.62, \underline{\mathrm{p}}<.001$ for 0s ITIs, 1.5s ITIs, and No ITIs, respectively). A further increase in performance was observed after the completion of Rate training, for 0s ITIs and No ITIs training $(\underline{t}(8)=-4.82, p=.001$ for 0s ITIs and $\underline{\mathrm{t}}(8)=-3.79, \mathrm{p}=.005$ for No ITIs) but not for 1.5s ITIs. The performance on the Retention test did not differ from the Post Rate test for any of the three training methods. When the Multi-trial presentation mode was used, subjects in the 0s ITIs and 1.5s ITIs groups showed significant improvement on the Post Accuracy test $(\underline{t}(9)=-3.28, \underline{p}=.009$ and $\underline{t}(9)=-$ $4.05, \mathrm{p}=.003$, respectively). Subjects in all conditions showed an increase in rate of responding after Rate training (tos $(9)=-5.56$ and -7.39 for $0 \mathrm{~s}$ ITIs and $1.5 \mathrm{~s}$ ITIs, respectively, $\mathrm{ps}<.001$, and $\underline{\mathrm{t}}(7)=-9.70, \underline{\mathrm{p}}<.001$ for No ITIs). There was a significant drop in rate of correct responding for the 1.5 s ITIs group $(\mathrm{t}(9)=5.21, \mathrm{p}=.001)$ on the Retention test, but performance did not change during the two week layoff period for the other two groups, 0s ITIs and No ITIs.

The mean number of correct responses to math problems presented in binary numbers for both Trial and Multi-trial presentations is shown in Table 7. After completing Accuracy training, subjects performed faster when the math problems were 


\section{Table 7.}

Mean Number of Correct Response to Math Problems Presented in Binary Numbers for Trials and Multi-trial Presentation Modes on All Tests, Collapsed Across Conditions.

\begin{tabular}{lllll}
\hline Presentation & Pretest & Post & Post & Retention \\
mode & 0.8 & 3.4 & 5.7 & 5.3 \\
\hline Trial & 0.7 & $2.3^{*}$ & $7.1^{*}$ & 5.2 \\
\hline
\end{tabular}

$* \mathrm{p}<.01$ 
presented using the Trial method than the Multi-trial method, or 3.4 and 2.3 correct responses per minute, respectively $(\underline{\mathrm{t}}(27)=-3.35, \underline{\mathrm{p}}=.002)$. However, after Rate training, this pattern was reversed as subjects responded faster when the Multi-trial presentations were used as opposed to Trial presentations, 7.1 versus 5.7 correct response, respectively $(\underline{\mathrm{t}}(28)=2.90, \underline{\mathrm{p}}=.007)$.

No differences in latency of responding to math problems presented in binary numbers were found between the three training conditions, regardless of presentation mode and test (Pretest through Retention).

A comparison of Figures 3, 4, and 5 shows that response rate, like accuracy, was a function of the type of task being tested. As shown in Tables 8 and 9, subjects generally responded the fastest to trained binary numbers, then at an intermediate rate to untrained numbers, and the slowest to math problems presented in binary numbers. This trend was consistent for all three training conditions regardless of presentation mode. No interaction was found between training method and type of testing task. Therefore, the data were collapsed across conditions and a statistical analysis using repeated measures analysis of variance (ANOVA) and paired sample t-tests conducted to compare the rates of correct responding to the three different tasks at both presentation modes for all tests throughout training (Pretest through Retention test). As shown in Tables 8 and 9, significant main effects at $\mathrm{p}<.001$ were found for type of task on all tests (Pretest, Post accuracy, Post rate, Retention) regardless of presentation mode. The mean rates of responding to the three types of trials at all tests are shown in Tables 8 and 9, along with 


\section{Table 8.}

The Mean Rate of Correct Responding for All Subjects to Trained and Untrained Binary Numbers, and Math Problems Presented in Binary on All Tests for Trial Presentations, Including Degrees of Freedom (Df) and F values for a Repeated Measures Analysis of Variance of the Three Tasks. The Lower Panel Shows Simple Comparisons Between Tasks at All Tests where $\mathrm{T}=$ Trained Trials, $\mathrm{U}=$ Untrained Trials, and $\mathrm{M}=$ Math Trials.

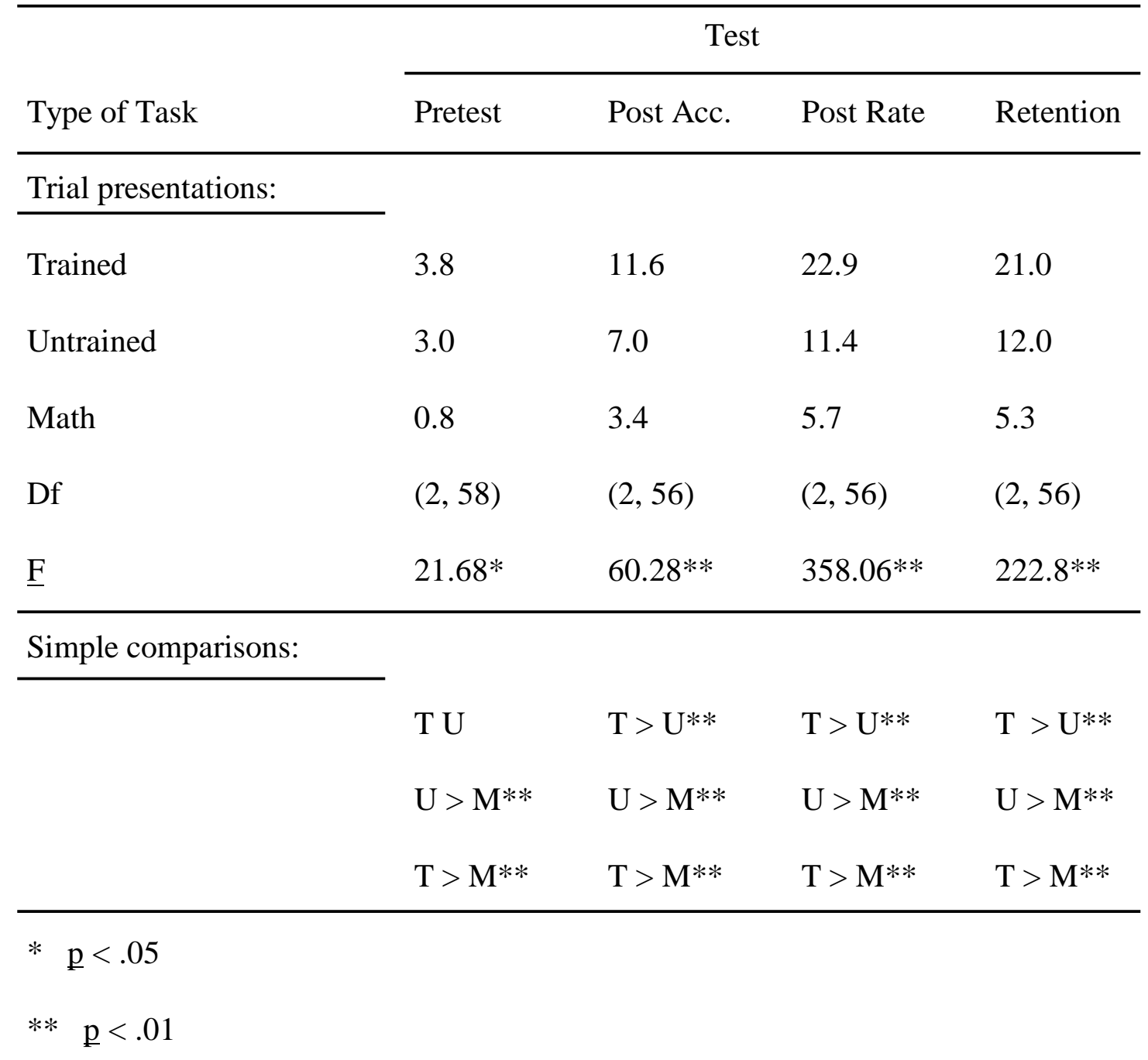




\section{Table 9.}

The Mean Rate of Correct Responding for All Subjects to Trained and Untrained Binary Numbers, and Math Problems Presented in Binary on All Tests for Multi-trial

Presentations, Including Degrees of Freedom (Df) and F values for a Repeated Measures Analysis of Variance of the Three Tasks. The Lower Panel Shows Simple Comparisons Between Tasks at All Tests where $\mathrm{T}=$ Trained Trials, $\mathrm{U}=$ Untrained Trials, and $\mathrm{M}=$ Math Trials.

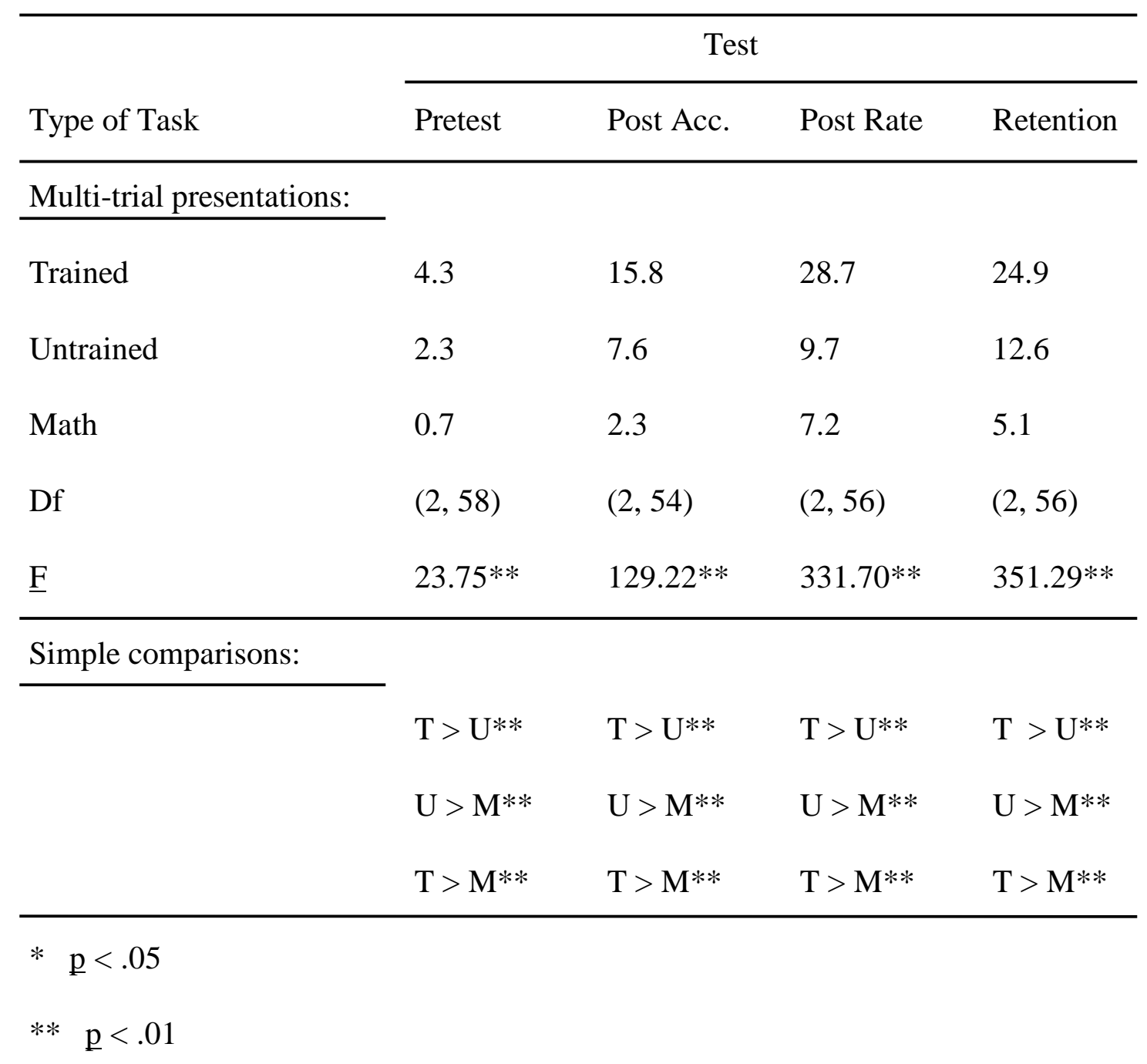


degrees of freedom and $\mathrm{F}$ values for the ANOVA. The t-test simple comparisons are also reported in the tables. They showed that all but one comparison was significantlydifferent at $\mathrm{p}>.001$. The only non-significant comparison was on the difference between responding to trained and untrained binary numbers when Trial presentations were used.

A repeated measure ANOVA was conducted to test for any interaction between order of testing, training effects, and testing administrations, but none were found.

\section{Discussion}

The purpose of this study was to evaluate the effectiveness of three training methods for developing fluency. Fluency was evaluated with respect to retention and performance on application (untrained binary numbers) and adduction tasks (math problems in binary). The main results of the study showed that all training methods produced significant learning and retention, but they differed in a number of subtle ways that may be important. Some of the results support further studies needed for clarification.

\section{Effectiveness of training}

All three methods were effective in teaching subjects to translate binary numbers into decimal numbers. Accuracy of responding on trained binary numbers increased significantly between Pretest and Post Accuracy test. Accuracy remained the same throughout rate training and was maintained on a Retention test. Rate of correct 
responding also increased after accuracy and rate training for all training methods and was maintained on most tests of retention.

The three training methods were also effective in producing changes in rate and accuracy of translating novel binary numbers into their decimal equivalents and calculating binary addition and subtraction problems. Accuracy and rate of responding increased significantly as a result of accuracy training. Rate of responding to these tasks also increased after rate training. In most cases rate of responding was maintained or increased even further on tests of Retention. These significant changes in performance on these related quantitative skills were achieved in a relatively short period of time. Time spent in training was 61 minute on the average with a rang from 4 minutes to 157 minutes, indicating the effectiveness of repeated practice with a computerized training package.

\section{Efficiency of training}

The experiment revealed significant differences between methods that might be of interest. Probably the most important were the differences in the amount of practice and time it took subjects to achieve mastery of translating binary numbers into decimal numbers. Subjects who received No ITIs training only took 29 one-minute timings and about 700 training trials on the average to meet the rate criterion, while it took over twice as many trials, 1423 , and time, 60 one-minute timings, for 0 s ITIs subjects to reach the same criterion. As the $1.5 \mathrm{~s}$ ITIs subjects were yoked to 0s ITIs subjects, they underwent the same amount of training, but it took them over 90 one-minute timings to finish. 
These differences were significant and indicate that No ITIs training is more efficient than 0s ITIs, which in turn is more efficient than 1.5s ITIs training. These findings are bolstered by differences in response rates to the different methods for presenting the trained binary numbers on tests. Subjects generally responded faster when the Multi-trial method was used than when the Trials methods was used. These differences were significant on all posttests involving trained binary numbers.

These findings suggest that presentation mode affects the rate at which subjects can respond. Subjects respond faster when multiple tasks are presented as opposed to the one task at a time, even when single tasks were presented with fast computer technology. These findings are consistent with speculations that are prevalent in the literature on fluency training and Precision Teaching (Binder, 1988; Binder, 1993; Johnson \& Layng, 1996) about the superiority of No ITIs methods over typical discrete trial methods. When presented with multiple trials in a single workspace, subjects may begin to respond to a new problem while still responding to a previous one (K. R. Johnson, personal communication, May, 1997). This idea is supported by research on perceptual span in reading, where subjects appear able to extract useful information from about 15 character positions from a fixation point (Rayner \& Pollatsek, 1989). Subjects are, however, prevented from doing this when discrete trial methods such as $0 \mathrm{~s}$ or $1.5 \mathrm{~s}$ ITIs are used and subjects' responding is slowed down. Interestingly, presentation mode and increased rate of responding did not seem to affect accuracy of responding, as accuracy was similar for all training conditions regardless of presentation mode and the 
rate allowed by that type of presentations. This provides an efficiency justification for the use of training methods, like No ITIs, that facilitate high rates of responding. The more a student can practice within a certain period of time without adversely affecting performance, the better.

Despite procedural differences between 0s and No ITIs, the terminal response rates over the last few one-minute sessions of rate training were almost identical at 29 responses per minute. The rate for $1.5 \mathrm{~s}$ ITIs was much lower at 17 responses per minute. The latencies of responding, however, were almost identical for all training methods. Therefore, the relatively low rate for $1.5 \mathrm{~s}$ ITIs training subjects was not a result of longer response latencies, but rather it was due to the imposed $1.5 \mathrm{~s}$ intervals between trials. Interestingly, this deliberate manipulation of rate did not appear to affect performance on tests either directly after rate training, or on a retention test. This contradicts discussion in the Precision Teaching literature that suggests that higher rates of responding should yield better training outcomes (Lindsley, 1996a, 1996b).

\section{Important differences in test performance}

Some differences in test performance, however, were found between subjects in the ITI training conditions and subjects who received No ITIs training. Subjects in both ITI conditions responded faster to trained binary numbers presented in Trials on the Post Rate test than did subjects undergoing No ITIs training. The Os ITIs subjects also responded faster than the No ITIs subjects on a test of Retention when using Trials procedures. Similar differences were found when trained binary numbers were presented 
using Multi-trials; $1.5 \mathrm{~s}$ ITIs subjects outperformed No ITIs on the Post Rate test and 0s ITIs subjects outperformed the No ITIs group on the Retention test. A related difference between the conditions was found on Retention test performance for trained binary numbers presented using Multi-trials. For subjects who received 1.5s ITIs and No ITIs training there was a significant decrease in rate of correct responding on the Retention test from the Post Rate test. No such decrease was observed for subjects in the 0s ITIs training condition. Although these between-condition differences suggest differences between the training conditions, whether the differences are due to characteristics of the training methods or to differing amounts of practice remains unclear. This will be discussed shortly.

Another significant finding was a progressive decrease in rate of responding from trained binary to untrained binary numbers to math problems presented in binary regardless of training condition. Subjects responded to untrained binary numbers at about half the rate they responded to trained binary numbers. When compared to untrained binary numbers, response rate to math problems presented in binary was also halved. A similar trend was observed for accuracy of responding between the three testing tasks. Accuracy was generally lower for math problems presented in binary than for trained and untrained binary numbers. Subjects responded most accurately to trained binary numbers.

These differences indicate two important points. First, these application and adduction tasks are good test tasks for future experimentation because they allow for 
improvement that may result from further manipulation of training. Second, these differences evoke questions about the current adequacy of functional definitions of fluency (RESAA). Johnson \& Layng (1996) stated that fluency has been achieved when training results in retention, endurance, stability, application and adduction, but they gave no indication of the levels of performance required for each of these outcomes. Retention, endurance, and stability requirements may be fairly straightforward. If the student performs as well on a task after a certain period of no practice or on extended timings and under conditions of distraction, then retention, endurance, and stability have been achieved. A problem arises, however, when testing for application and adduction because these tasks differ from the initial training task.

By definition, application and adduction tasks involve responses in the presence of different stimuli than on the trained tasks. These differences make it difficult to assume that the same rates will apply to these tasks as the trained tasks, which begs the question of how much rates and possibly accuracy on an application or adduction task can deviate from the initial training task to fulfill fluency requirements. Maybe any positive change in rate and accuracy on these types of tasks indicates fluency. This, however, does not seem very pragmatic because it does not distinguish fluent from nonfluent behaviors except in an extreme case of no improvement of application or adduction performance. Binder (1996) briefly addressed this problem by acknowledging the difficulty of the present criteria for fluency. He states that "Simply demonstrating in a systematic fashion that higher performance frequencies improve outcomes in one or 
more of the three categories for any behavior class is itself a notable accomplishment..." (Binder, 1996, p. 174). This indicates that fluency should not be thought of as an all or none phenomena, but on a continuum, i.e., there are different levels of fluency that correspond to different levels of behavioral outcomes. Most likely, all training methods produce fluency to some extent. Some, however, may be more effective than others. In this study, subjects responded as accurately and as frequently on a test of retention as they did after training. They also responded correctly to application and adduction tasks, but their rates and accuracy were lower than on the trained tasks. It is tempting to conclude that the subjects achieved fluency, but the confusion about what fluency does and does not entail suggests that conclusions concerning differences and lack of differences between methods need to be tentative. Lindsley (1996a, 1996b), for example, suggested that in order to achieve fluency the training rates need to reach at least 40 responses per minute. This counters the notion conveyed by functional definitions (Binder, 1996; Johnson \& Layng, 1996) and contrasts with Binder's (1996) suggestion that fluency rates have to be empirically validated for each type of training. Lindsley's criterion suggests, however, that the rate criterion used for 0s and No ITIs was not high enough. If a higher criterion had been used, perhaps it would have brought about more salient differences in the behavioral outcomes of the three training conditions under investigation.

It also should be acknowledged at this point that the number of statistical comparisons conducted may have inflated the statistical significance of some of the 
comparisons (Type 1 error). In fact, some of the reported differences between the ITI conditions and the No ITIs condition were actually eliminated when more stringent comparisons (ANOVA w/Scheffe comparison test) were used. However, considering the rational for conducting this study, which was a comparison of the three training methods, the use of t-tests for planned comparisons was justified.

\section{Future questions.}

One of the more interesting questions evoked from these data is why the No ITIs subject performed as well as the 0 s and $1.5 \mathrm{~s}$ ITIs subjects when tested on application and adduction tasks despite undergoing only half the amount of practice. Repeated findings suggest that practice makes perfect, i.e., that performance improves monotonically as a function of the amount of practice (Stevens \& Savin, 1962; Bloom, 1986; Carlson, Sullivan, \& Schneider, 1989; Ericsson, Krampe, \& Tesch-Romer, 1993; LaBerge \& Samuels, 1974). This predicts that subjects from the two ITIs conditions should do better than those from the No ITIs condition.

One possible reason for this not happening in the current study is that rate training using "free-operant" (No ITIs) procedures may produce better learning than the two ITI techniques under investigation. In other words, the method itself may counteract the practice effects such that subjects in a No ITIs condition perform as well as the subjects in discrete trials conditions, who receive more practice. This would be consistent with claims made that methods used for developing fluent behaviors should allow the learner to control his own pace (Binder, 1988; Binder, 1993; Johnson \& Layng, 
1996; Lindsley, 1996). Consistent with this view is the emphasis on rate of responding as the best predictor of performance, not practice.

It is also possible that the design used in this study was not powerful enough to always pick up the differences between the three different training methods. As can be seen in figures 3, 4 and 5, subjects in the No ITIs condition generally responded slower than subjects from the ITI conditions. This is especially salient for trained binary numbers and to some extent for untrained binary numbers and math in binary. Although most of these comparisons were not statistically significant they are consistent with the significant differences found between 0s and No ITIs conditions on Post Rate and Retention tests.

Further, despite differences in practice and rate between training condition, all involved overlearning (Dougherty \& Johnston, 1996). All subjects received extensive additional practice after achieving a criterion. Assuming that all subjects had reached optimal levels of performance (asymptote of rate and accuracy) it could be argued that such overlearning made it difficult to distinguish differences between the three training conditions on the basis of their performance on tests.

In addition, it is important to note again that practice was confounded with method of presenting the tasks during rate training in the current experiment. Further research aimed at getting around this confound is needed. For example, it might be appropriate to run two more conditions, one using No ITIs training that is yoked to the amount of practice received by the 0s ITIs subjects, and another using 0s ITIs training 
that is yoked to the amount of practice received by the No ITIs subjects. Although these modifications control for practice, it may still be difficult to draw definite conclusions from the results if there are differences in rate between the groups. Based on the results of the present study, the No ITI subjects will be likely to obtain higher rates with the same amount of practice. Thus the practice/method confound will be replaced with a rate/method confound. Untangling rate and method may require more elaborate procedures.

In light of the emphasis on rate of responding to produce fluency, a second interesting question arises from the 1.5s ITIs subjects doing just as well on tests as $0 \mathrm{~s}$ ITIs and No ITIs subjects, in spite of being trained at half the rate. According to most of the discussions of methods used for achieving fluency, rate is important (Johnson \& Layng, 1996). For example, Lindsley (1996a) claims that "true" fluency cannot be reached when rates do not exceed 20 responses per minute. A comparison of the 0 s and 1.5 ITIs training methods shows no difference in retention, application, and adduction despite the 0 s ITIs subjects achieving a rate of 29 responses per minute and the $1.5 \mathrm{~s}$ ITIs subjects responding at only 17 responses per minute.

This lack of differences suggest that rate of responding during training is not important. In this case at least, it seems that most effects of rate are shadowed by practice effects, i.e., equal amounts of practice seem to predict equal behavioral outcomes regardless of rate. This is consistent with studies on the effects of practice on learning (Ericsson, Krampe, \& Tesch-Romer, 1993). Latencies of responding, however, 
were the same for the $0 \mathrm{~s}$ and $1.5 \mathrm{~s}$ ITIs training conditions. This is not surprising given equal amounts of practice for both conditions because practice reduces latencies of responding (Ericsson, Krampe, \& Tesch-Romer, 1993; LaBerge \& Samuels, 1974). This suggests the importance of latencies predicting fluency outcomes, not necessarily rate. This makes intuitive sense. If time is a critical element of fluent performance then the time from when a stimulus is presented to when a response begins would seem to be a critical measure. Other measures of time may be dependent on duration of responses, ITIs, consequences, and other constraints placed on responding by the environment. In a sense, the whole discussion of discrete trials and free-operant methods or, as re-framed here, between experimenter imposed and subject imposed constraints on responding, might be answered by focusing on latencies. Procedures that decrease latencies increase the likelihood of achieving the performance outcomes of fluency. This includes ratebuilding procedures because most often rates and latencies are negatively correlated. This also includes methods of presenting stimuli that obtain high rates, like the no ITIs tested here, which show that decreased latencies can be achieved efficiently.

Another explanation for the lack of differences between the two ITI conditions comes from basic research on behavioral momentum. Behavioral momentum or response strength are terms used to describe persistence of responding under new conditions or in the face of changed contingencies (Lattal, 1989). It has been suggested that rate of responding is correlated with response strength, where high rates are less resistant to change than low rates (Skinner, 1938). This position is consistent with 
Precision Teachers's emphasis on rate of responding, where it is predicted that higher rates improve performance on trained tasks in the face of distraction (retention, endurance, and stability) and on related tasks (application and adduction). Some studies, however, have shown that high rates of responding may actually be less resistant to change than low rates and that other variables, such as reinforcement frequency and magnitude, may be responsible for behavioral resistance (Nevin, 1974; Lattal, 1989). Because higher rates of responding in the educational literature typically produce higher rates of reinforcement, it may be that the relatively high frequency of reinforcement produced by high response rates, not the response rates themselves, makes responding resistant to change.

The emphasis put on rate of responding within the Precision Teaching paradigm can be adapted to the rationale about the importance of reinforcement rate. As in basic research, higher rates of responding lead to higher rates of reinforcement than do low rates of responding if responding is reinforced on ratio schedules. Therefore, high rate training using ratio schedules should result in skills that do not decrease over time (e.g., retention) and have an increased chance of maintenance in the face of new contingencies (e.g., application) than skills trained with low rates of responding. If equivalent rates of reinforcement were ensured during training of high and low rates, however, low rate behavior should be more resistant to change than high rate behavior. In the present study, a comparison between the $0 \mathrm{~s}$ and $1.5 \mathrm{~s}$ ITIs training conditions provides one assessment of the effects of rate of responding on fluency related outcomes. Virtually no 
effects were found, even though the $1.5 \mathrm{~s}$ ITIs subjects responded at lower rates. At first glance, this is not consistent with behavioral momentum. However, these nondifferences can be explained with reference to the relation between reinforcement frequency and magnitude. Although there were no differences in rate of reinforcement between the two training methods, there were differences in reinforcement magnitude. The 0s ITIs subjects normally responded correctly to more trials during each timing, which results in more points being added to their score at the end of each timing, thus the magnitude of reinforcement was higher. Thus, the 1.5s ITIs subjects' responding was strengthened by low rates of responding and the 0s ITIs subjects' responding was strengthened by magnitude of reinforcement such that no differences were found. Further research can be conducted to ascertain if the principles of behavioral momentum found in basic animal laboratories hold for human subjects in educational research. For example, it is possible to manipulate rate of responding while holding practice, and rate and magnitude of reinforcement constant. If the above principles apply, low rates should predict better training outcomes than higher rates.

As described earlier the design of the study may have precluded finding differences. If a more powerful design had been used, perhaps differences would have been found between the $0 \mathrm{~s}$ and $1.5 \mathrm{~s}$ ITIs conditions. The fact that $1.5 \mathrm{~s}$ ITIs subjects' performance decreased on two occasions between Post Rate and Retention tests may suggest that rate had some effects. The analysis of latencies, however, suggests that this is not a fruitful avenue to pursue. Even if ITIs were increased even further to manipulate 
rate, the fact that subjects' latencies were nearly identical suggests that the critical temporal measure of responding is affected by practice, not rate.

A third interesting addition to this study would be to determine the minimum rates at which fluency is achieved, and then parametrically manipulate these rates to see what effects they have on retention and performance on application and adduction tests. According to the literature on Precision Teaching, fluency is evaluated with respect to the behavioral outcomes of specific rates of responding, i.e., retention, endurance, stability, application, and adduction (Johnson \& Layng, 1996). As noted earlier, however, a change in application and adduction can be achieved while leaving room for improvement. In addition, some have claimed that there are certain minimum rates of responding that are required for achieving fluency, such as 40 responses per minute (Lindsley, 1996b).

Manipulation of this sort has important implications in education as it suggests grounds for discussing not only the methods used for achieving fluency, but also the skills that should be trained to high rates (Hazlett, Chase, \& Munson, 1998). If on one hand fluency can only be achieved through training of extremely high rates, it would confine fluency training to very simple basic skills. Responding on composite tasks frequently takes long periods of time due to the complexity of the response. Therefore, complex composite skills may not lend themselves to rate training. If on the other hand, relatively high rates are not crucial, fluency training may be important for any skill, but some skills will be trained to lower rates than others to produce the behavioral outcomes 
associated with fluency. Consequently, educators will not have to decide that some skills should be taught with rate criteria and others should not. Rather, they will have to determine the rate criteria that predict important behavioral outcomes like retention, endurance, stability, application and adduction. This would be a step in the direction of solving the dilemma that has arisen about the appropriateness of rate training on component and composite skills (Hazlett, Chase, \& Munson, 1998), as well as the controversy about the use of methods for producing fluency.

\section{Conclusions}

A few firm conclusions can be drawn from this study. First, the three training methods under investigation differed in terms of efficiency of training. No ITIs training was the most efficient and 1.5s ITIs training was the least. All methods were effective in teaching translation of binary numbers and produced behavioral outcomes that have been correlated with fluency, i.e., retention, application and adduction. Some differences were found between the ITI conditions and the No ITIs condition. These differences, however, were confounded with differences in practice. Consequently, the study did not provide definite answers as to the differential effectiveness of these two types of training methods. Finally, no differences were found between the 0s ITIs and 1.5s ITIs subjects despite differences in rate. Although this lack of differences might be attributed to the lack of power of the experiment to find differences, similar latencies of responding suggest that both conditions had sufficient practice to achieve fluency outcomes. Further 
research is needed to enhance the understanding of those different methods of fluency training. 


\section{References}

Andronis, P. T., Layng, T. V. J., \& Goldiamond, I. (1997). Contingency adduction of "symbolic agression" by pigeons. The Analysis of Verbal Behavior, 14, 5-17.

Beck, R. \& Clement, R. (1991). The Great Falls Precision Teaching Project: An historical examination. Journal of Precision Teaching, 8(2), 8-12.

Binder, C. (1996). Behavioral fluency: Evolution of a new paradigm. The Behavior Analyst, 19, 163-197.

Binder, C. (1993). Behavioral fluency: A new paradigm. Educational Technology, $\underline{10}, 8-14$.

Binder, C. (1988). Precision Teaching: Measuring and attaining exemplary academic achievement. Youth Policy, 10(7), 12-15.

Bloom, B. S. (1986, February). The hands and feet of genius: Automaticity. Educational Leadership, 70-77.

Carlson, R. A., Sullivan, M. A., \& Schneider, W. (1989). Component fluency in a problem-solving context. Human Factors, 31(5), 489-502.

Dougherty, K. M., \& Johnston, J. M. (1996). Overlearning, fluency and automaticity. The Behavior Analyst, 19, 289-292.

Ericsson, K. A., Krampe, R. T., \& Tesch-Romer, C. (1993). The role of deliberate practice in the acquisition of expert performance. Psychological Review, 100, $363-406$. 
Ferster, C. B. (1953). The use of the free operant in the analysis of behavior. Psychological Bulletin, 50(4), 263-274.

Hazlett, K. H., Chase, P. N., \& Munson, K. J. (1998) Potential costs and benefits of computerizing Precisions Teaching in mathamatics. Paper presented at the annual meeting of The Association for Behavior Analysis, Orlando, FL.

Howell, K. W., \& Lorson-Howell, K. A. (1990). What's the Hurry?: Fluency in the Classroom. Teaching Exceptional Children, 22(3), 20-23.

Johnson, K. R., \& Layng, T. V. J. (1992). Breaking the structuralist barrier. The American Psychologist, 47, 1475-1490.

Johnson, K. R., \& Layng, T. V. J. (1994). The Morningside model of generative instruction. In R. Gardner, D. M. Sainato, J. O. Cooper, T. E. Heron, W. L. Heward, J. W. Eshleman, and T. A. Grossi (Eds.). Behavior Analysis in Education. (pp. 173-197). Belmont, CA: Brooks/Cole.

Johnson, K. R., \& Layng, T. V. J. (1996). On terms and procedures: Fluency. The Behavior Analyst, 19, 281-288.

Keller, F. S. (1968). “Goodbye teacher...” Journal of Applied Behavior Analysis, 1, 79-89.

LaBerge, D., \& Samuels, S. J. (1974). Toward a theory of automatic informationprocessing in reading. Cognitive Psychology, 6, 293-323.

Lattal, K. A. (1989). Contingencies on response rate and resistance to change. Learning and Motivation, 20, 191-203. 
Lindsley, O. R. (1990). Precision teaching: By teachers for children. Precision Teaching, 22, 10-15.

Lindsley, O. R. (1996a). The four free-operant freedoms. The Behavior Analyst, 19, 199-210.

Lindsley, O. R. (1996b). Is fluency free-operant response-response chaining? The Behavior Analyst, 19, 211-224.

Miller, A. D., \& Heward, W. L. (1992). Do your students really know their math facts? Intervention in school and clinic, 28, 98-104.

Munson, K. J. (1998). Behavioral fluency. Unpublished doctoral dissertation, West Virginia University, Morgantown.

Nevin, J. A. (1974). Response strength in multiple schedules. Journal of the Experimental Analysis of Behavior, 21, 389-408.

Rayner, K., \& Pollatsek, A. (1989). The psychology of reading. Englewood Cliffs, N. J: Prentice Hall.

Skinner, B. F. (1938). Behavior of organisms. Englewood Cliffs, N. J: Prentice Hall.

Skinner, B. F. (1968). The technology of teaching. Englewood Cliffs, N. J: Prentice Hall.

Stevens, J. C., \& Savin, H. B. (1962). On the form of learning curves. Journal of the Experimental Analysis of Behavior, 5, 15-18.

Wingert, P. (1996, December 2). The sum of mediocrity. Newsweek, 96. 
Appendix A - Subject Recruitment Form

\section{Subject Recruitment Sign-up Form}

Name of Study: Fluency and Controlled-Operant Training Methods

Participants are needed for an experiment using voice recognition computers to be conducted in the Department of Psychology. Only persons who have completed Math 3 or Math 28 and are not Computer Science majors or minors will be accepted for the experiment. The experiment will be conducted in a laboratory in Oglebay Hall during the 1998 spring semester. Participants have the opportunity to earn approximately $\$ 5$ per hour of participation, which also includes $\$ 6$ attendance bonus for coming to all scheduled sessions. It will take approximately 3-6 1-hour sessions to complete the experiment.

Please write your name, phone number and the best time to call below.

Name:

1.

2 .

3.

4.

5.

6.

7.

8.

9.

10.

11.

.

.

.

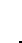

.

.

.

.

.
Phone:

Best time to call: 
Appendix B - Subject Selection Test

\section{Subject Selection Test}

Please write your answer in the space provided.

1. The binary number 00101 is equal to the decimal number

2. The binary number 00111 is equal to the decimal number

3. The binary number 10101 is equal to the decimal number

4. The binary number 00100 is equal to the decimal number

5. The binary number 01001 is equal to the decimal number

6. The binary number 11100 is equal to the decimal number

7. The binary number 00110 is equal to the decimal number

8. The binary number 11101 is equal to the decimal number

9. The binary number 10000 is equal to the decimal number

10. The binary number 10001 is equal to the decimal number 


\section{Appendix C - Informed Consent Form for 0s and 1.5s ITIs training conditions. Informed Consent Form}

Fluency: A Comparison of the Effectiveness of Three Computerized Fluency Training Methods

Introduction: I, have been invited to participate in this research study which has been explained to me by Finnur Oddsson. This research is conducted to fulfill requirements for a Masters degree in Psychology at West Virginia University.

Purpose of the Study: The purpose of this study is to compare the effectiveness of three computerized training methods to teach mathematical skills. The study will compare methods for presenting mathematics problems on a computer screen.

Procedures: During this study I will learn to translate binary numbers into decimal numbers. The training method used involves presenting the numbers, one at a time, on a computer monitor. My task is to translate the numbers into decimal numbers. Throughout the study, my performance will be tested using paper and pencil and computerized tests. It will take me about 6-10 hours to complete my participation in the study. Approximately 30 subjects will participate.

Risks and Discomforts: There are no known or anticipated discomforts involved in serving as subject in this study.

Benefits: I understand that this study may not be of direct benefit to me, but might improve my academic skills. The knowledge gained from it may be of benefit to others. My participation in this study will allow me to receive extra credit for classes in which I am eligible to do so. However, there are other ways for me to earn extra credit for these classes. I understand that I may gain up to \$xx for my performance during each experimental session and \$xx attendance bonus for not missing any sessions without notifying the experimenter. I understand that if I miss two or more scheduled session, and if I do not call in advance of missing a session, I may be dropped from the experiment and forfeit my bonus. Still, I will receive the earnings that I have accumulated. My earnings will be paid to me when I complete my participation.

Contact Persons: For more information about this study, I can contact Finnur Oddsson, at 293-2001 (ext. 826), or his supervisor, Dr. Philip N. Chase, at 293-2001 (ext. 626). For information regarding my rights as a research subject, I may contact the Executive Secretary of the Institutional Review Board at 293-7073.

Confidentiality: I understand that any information about me obtained as a result of my participation in this study will be kept as confidential as legally possible. I also understand that my research record, just like hospital records, may be subpoenaed by court order or may be inspected by federal regulatory authorities. In any publications that result from this research neither my name nor any information from which I might be identified will be published without my consent.

Voluntary Participation: Participation in this study is voluntary. I understand that I am free to withdraw my consent to participate in this study at any time. Refusal to participate or withdrawal will involve no penalty or loss of benefits and will not affect my grades or class standing. I have been given the opportunity to ask questions about the research, and I have received answers concerning areas I did not understand. 
Upon signing this form, I will receive a copy.

I willingly consent to participate in this study.

Signature of Subject

Signature of Investigator
Date

Date
Time

Time 


\title{
Appendix D - Informed Consent Form for the No ITIs training condition.
}

\section{Informed Consent Form}

\author{
Condition III. \\ Fluency: A Comparison of the Effectiveness of Three Computerized Fluency Training Methods
}

Introduction: I, have been invited to participate in this research study which has been explained to me by Finnur Oddsson. This research is conducted to fulfill requirements for a Masters degree in Psychology at West Virginia University.

Purpose of the Study: The purpose of this study is to compare the effectiveness of three computerized training methods to teach mathematical skills. The study will compare methods for presenting mathematics problems on a computer screen.

Procedures: During this study I will learn to translate binary numbers into decimal numbers. The training method used involves presenting many binary numbers simultaneously on a computer monitor. My task is to translate the numbers into decimal numbers. Throughout the study, my performance will be tested using paper and pencil and computerized tests. It will take me about 6-10 hours to complete my participation in the study. Approximately 30 subjects will participate.

Risks and Discomforts: There are no known or anticipated discomforts involved in serving as subject in this study.

Benefits: I understand that this study may not be of direct benefit to me, but might improve my academic skills. The knowledge gained from it may be of benefit to others. My participation in this study will allow me to receive extra credit for classes in which I am eligible to do so. However, there are other ways for me to earn extra credit for these classes. I understand that I may gain up to \$xx for my performance during each experimental session and $\$ \mathrm{xx}$ attendance bonus for not missing any sessions without notifying the experimenter. I understand that if I miss two or more scheduled session, and if I do not call in advance of missing a session, I may be dropped from the experiment and forfeit my bonus. Still, I will receive the earnings that I have accumulated. My earnings will be paid to me when I complete my participation.

Contact Persons: For more information about this study, I can contact Finnur Oddsson, at 293-2001 (ext. 826), or his supervisor, Dr. Philip N. Chase, at 293-2001 (ext. 626). For information regarding my rights as a research subject, I may contact the Executive Secretary of the Institutional Review Board at 293-7073.

Confidentiality: I understand that any information about me obtained as a result of my participation in this study will be kept as confidential as legally possible. I also understand that my research record, just like hospital records, may be subpoenaed by court order or may be inspected by federal regulatory authorities. In any publications that result from this research neither my name nor any information from which I might be identified will be published without my consent.

Voluntary Participation: Participation in this study is voluntary. I understand that I am free to withdraw my consent to participate in this study at any time. Refusal to participate or withdrawal will involve no penalty or loss of benefits and will not affect my grades or class standing. I have been given the opportunity to ask questions about the research, and I have received answers concerning areas I did not understand. 
Upon signing this form, I will receive a copy.

I willingly consent to participate in this study.

Signature of Subject

Date

Time

Signature of Investigator

Date

Time 
Appendix E - Pre-training.

\section{How to convert a binary number to a decimal number}

1.

A decimal number has a base of 10 and is written in a form that uses the digits from 0-9 (ten digits). For example 1, 9, 76,354, 1298, etc. A binary number, however, has a base of 2 and is therefore written in a form that uses only two digits, i.e., 0 and 1. For example 1, 10, 101, 10011, 101001, etc.

Write any two binary numbers that are different from those above:

Binary:

Check you answers:

Binary: 1001, 1111 (for example)

2.

To convert a binary number into a decimal number, you have to know the column position of the digits. The column position of each digit is determined from right to left. The first column on the right is column 0 , the second is column 1, the third is column 2 , etc. In the number " 456 " for example, the digit " 6 " is in column zero, " 5 " is in column one, and " 4 " is in column 2.

What is the column position of the "0" in the following numbers?
a) 110111
b) 2401
c) 6270
d) 907776 
3.

Just as the column position in the decimal number system indicates decimal units (for example, ones, tens, hundreds, etc.), the column position in the binary number system indicates binary units. The binary units are powers of 2 similar to how decimal units are powers of 10 . For binary numbers, column position zero is 2 to the 0 power, column position one is 2 to the $1^{\text {st }}$ power, column position two is 2 to the $2^{\text {nd }}$ power, etc. For example, $2^{0}=1,2^{1}=2,2^{2}=4,2^{3}=8$.

For binary numbers, what do the following column positions stand for?

a) column position 4 :

b) column position 5 :

Check you answers:

Ans: a) 2 to the $4^{\text {th }}$

b) 2 to the $5^{\text {th }}$

The column position indicates the power of 2 .

4.

To translate binary numbers into decimal numbers just multiply each digit of the number by 2 (for binary) and by the power indicated by the column position and add the products. For example the decimal equivalent of the binary number " 110 " is six. The calculation is the following: $1 \times 2^{2}+1 \times 2^{1}+0 \times 2^{0}=4+2+0=6$. Let's look at a few more examples:

\begin{tabular}{llc} 
Binary & Calculation & Decimal equivalent \\
\hline 1 & $1 \times 2^{0}=1$ & 1 \\
11 & $1 \times 2^{1}+1 \times 2^{0}=2+1$ & 3 \\
101 & $1 \times 2^{2}+0 \times 2^{1}+1 \times 2^{0}=4+0+1$ & 5
\end{tabular}

Note, that the digit zero in any column is always zero. This is understandable because zero times any number is always zero. Thus you can automatically calculate any column position with zero; it is always zero. Also, multiplying by one does not change the number because one times any number is always equal to that number. Thus, it is sufficient to identify the column positions that have the digit 1 and multiply the base, 2, by the corresponding power. Therefore the above calculation can be simplified:

\begin{tabular}{llc} 
Binary & Calculation & Decimal equivalent \\
\hline 1 & $2^{0}=1$ & 1 \\
11 & $2^{1}+2^{0}=2+1$ & 3 \\
101 & $2^{2}+2^{0}=4+1$ & 5
\end{tabular}


Now, try some yourself. Calculate the decimal equivalent of the following binary numbers:

Binary Calculation (if necessary) Decimal

a) 1001

b) 1010

Check you answers:

Ans: a) 9 b) 10

5.

When translating binary numbers to decimal numbers it is useful to memorize what each column stands for if the digit " 1 " is in it. For example, if the digit " 1 " is in column position 5 it is equivalent to the decimal number 32.

What is the decimal equivalent of the digit " 1 " in the following column positions?
Column \# $0=$
\# $1=$
\#2 =
\# 3 =
\# 4 =

Check you answers:

Ans: 1, 2, 4, 8, 16

\section{Test:}

Translate the following binary number into decimal numbers:

Binary Calculation (if necessary) Decimal equivalent
a) 0001
b) 1000
c) 0100
d) 10001
e) 11010

If you missed any, review the instructions again, and find out where you went wrong.

Ans. a)1, b)8, c)4, d)17, e)26 (Answers will not be given). 
Fluency and Controlled-Operant Training Methods

by

\title{
Finnur Oddsson
}

\begin{abstract}
The study compared the effectiveness three computerized training methods with respect to behavioral outcomes correlated with fluency. Subjects were trained to translate binary numbers into decimal numbers. Responses were made orally with the use of voice recognition software. One training method presented 50 stimuli on a computer monitor at a time (No ITIs). The other two methods (0s and 1.5s ITIs) presented stimuli separately on the monitor using discrete trials. Inter trial intervals were manipulated for the latter training methods. Results showed that all subjects achieved fluent performance on the training task. Subjects reached rate criterion faster and with less practice when No ITIs training was used as opposed to 0 s or $1.5 \mathrm{~s}$ ITIs training. Subjects trained with 0s and 1.5s ITIs, however, performed better than No ITIs subjects on tests immediately after rate training and also on tests of retention. Little differences were found between the training methods when tested on application and adduction tasks. No differences in test performance were found between the $0 \mathrm{~s}$ and $1.5 \mathrm{~s}$ ITIs despite considerable differences in rate of responding during training.
\end{abstract}


Fluency and Controlled-Operant Training Methods THESIS

Submitted to the Eberly College of Arts and Sciences

of

West Virginia University

In Partial Fulfillment of the Requirements for

The Degree of Master of Arts

by

Finnur Oddsson, B. A.

Morgantown, West Virginia

1998

APPROVAL OF EXAMINING COMMITTEE

Philip N. Chase, Ph.D., Chair

Kennon A. Lattal, Ph.D.

Date

Anne Watson, Ph.D. 